\title{
ADVANCES OF HYALURONIC ACID IN STEM CELL THERAPY AND TISSUE ENGINEERING, INCLUDING CURRENT CLINICAL TRIALS
}

\author{
E. López-Ruiz ${ }^{1,2,3,4}$, G. Jiménez ${ }^{2,3,4}$, L. Álvarez de Cienfuegos ${ }^{4,5}$, C. Antich ${ }^{2,3,4}$, R. Sabata ${ }^{6}$, J.A. Marchal ${ }^{2,3,4, \$}$ \\ and Patricia Gálvez-Martín' 6,7,\$,* \\ ${ }^{1}$ Department of Health Sciences, University of Jaén, Jaén E-23071, Spain \\ ${ }^{2}$ Biopathology and Regenerative Medicine Institute (IBIMER), Centre for Biomedical Research, \\ University of Granada, Granada E-18100, Spain \\ ${ }^{3}$ Department of Human Anatomy and Embryology and Excellence Research Unit \\ “Modeling Nature” (MNat), Faculty of Medicine, University of Granada, Granada E-18016, Spain \\ ${ }^{4}$ Biosanitary Research Institute of Granada (ibs.GRANADA), \\ University Hospitals of Granada-University of Granada, Granada E-18071, Spain \\ ${ }^{5}$ Department of Organic Chemistry, Faculty of Science, University of Granada, \\ University of Granada, UGR, C. U. Fuentenueva, Granada E-18071, Spain \\ ${ }^{6}$ Advanced Therapies Area, Bioibérica S.A.U., Barcelona E-08029, Spain \\ ${ }^{7}$ Department of Pharmacy and Pharmaceutical Technology, Faculty of Pharmacy, \\ University of Granada, Granada E-18071, Spain \\ $\S$ Theses authors contributed equally
}

\begin{abstract}
Hyaluronic acid (HA), as one of the main components of the extracellular matrix (ECM), plays a significant role in a multitude of biological processes involving cell migration, proliferation, differentiation, wound healing and inflammation. Thanks to its excellent biocompatibility, biodegradability and hygroscopic properties, HA has been used in its natural form for joint lubrication and ocular treatment. The chemical structure of HA can be easily modified by direct reaction with its carboxyl and hydroxyl groups. Recently, HA derivatives have been synthesised with the aim of developing HA-based materials with increased mechanical strength, improved cell interactions and reduced biodegradation and studied for regenerative medicine purposes, including cell therapy and tissue engineering. In this context, the present manuscript reviews HA applications from a basic point of view - including chemical modifications and cellular biology aspects related to clinical translation - and future perspectives of using biofabrication technologies for regenerative medicine. A detailed description of current clinical trials, testing advanced therapies based on combination of stem cells and HA formulations, is included. The final goal was to offer an integral portrait and a deeper comprehension of the current applications of HA from bench to bedside.
\end{abstract}

Keywords: Cell therapy, hyaluronic acid, tissue engineering, scaffold, encapsulation, stem cell.

*Address for correspondence: Patricia Galvez-Martin, PhD, Advanced Therapies Area, Bioibérica S.A.U., Barcelona E- 08029, Spain.

Email: pgalvez@bioiberica.com

Copyright policy: This article is distributed in accordance with Creative Commons Attribution Licence (http://creativecommons.org/licenses/by-sa/4.0/).

\begin{tabular}{llll}
\hline & List of Abbreviations & BM & bone marrow \\
& & BMAC & BM aspirate concentrate \\
2D & two dimensional & BMC & $\beta$-cyclodextrin \\
3D & three dimensional & CD & cardiosphere-derived cells \\
Ad & adamantane & CDCs & 1,2,7,8-diepoxyoctane \\
BDDE & butanediol-diglycidyl ether & DEO & diabetes mellitus \\
BDNF & brain-derived neurotrophic factor & DM
\end{tabular}




\begin{tabular}{|c|c|}
\hline DVS & divinylsulphone \\
\hline ECM & extracellular matrix \\
\hline EDC & $\begin{array}{l}\text { 1-ethyl-3-[3-(dimethylamino)- } \\
\text { propyl]-carbodiimide }\end{array}$ \\
\hline EPCs & endothelial progenitor cells \\
\hline eEPCs & embryonic EPCs \\
\hline EX 810 & ethylene glycol diglycidyl ether \\
\hline FDA & Food and Drug Administration \\
\hline FN & fibronectin \\
\hline GH & guest-host \\
\hline GlcA & glucuronic acid \\
\hline GlcNAc & N-acetyl-D-glucosamine \\
\hline HA & hyaluronic acid \\
\hline HAMC & hyaluronan and methylcellulose \\
\hline HAS & hyaluronic acid synthases \\
\hline HEMA & hydroxyethylmethacrylate \\
\hline IA & intra articular \\
\hline ICOAP & intermittent and constant pain score \\
\hline IKVAV & $\begin{array}{l}\text { isoleucine-lysine-valine-alanine- } \\
\text { valine }\end{array}$ \\
\hline IVD & intervertebral disc \\
\hline LME & L-leucine methyl ester \\
\hline MeHA & methacrylated HA \\
\hline MI & myocardial infarction \\
\hline MPCs & mesenchymal precursor cells \\
\hline MSCs & mesenchymal stem cell \\
\hline $\mathrm{N} / \mathrm{P}$ & not provided \\
\hline NSCs & neural stem and progenitor cells \\
\hline OA & osteoarthritis \\
\hline PBS & phosphate buffered saline \\
\hline PBSCs & peripheral blood stem cells \\
\hline PEDOT & poly 3,4-ethylenedioxythiophene \\
\hline PEG & polyethylene glycol \\
\hline PCL & poly( $\varepsilon$-caprolactone) \\
\hline PLA & poly(D,L-lactic acid) \\
\hline PLGA & poly(D,L-lactic-co-glycolic acid) \\
\hline PRP & platelet-rich plasma \\
\hline RA & rheumatoid arthritis \\
\hline RGD & arginine-glycine-aspartic acid \\
\hline rhBMP-2 & $\begin{array}{l}\text { human bone morphogenetic } \\
\text { protein-2 }\end{array}$ \\
\hline RPCs & retinal progenitor cells \\
\hline SDF-1 $1 \alpha$ & $\begin{array}{l}\text { recombinant stromal cell derived } \\
\text { factor- } 1 \text { alpha }\end{array}$ \\
\hline SFF & solid freeform fabrication \\
\hline TE & tissue engineering \\
\hline TEHV & tissue engineered heart valves \\
\hline UC-MSCs & umbilical cord MSCs \\
\hline UCB-MSCs & umbilical cord blood-derived MSCs \\
\hline VAS & visual analogue scale \\
\hline VICs & valvular interstitial cells \\
\hline WOMAC & Western Ontario and McMaster \\
\hline
\end{tabular}

\section{Introduction}

In recent decades, there has been an increasing interest in the development of regenerative approaches to repair or replace damaged tissues. Additionally, the continued development of several therapeutic strategies demands the use of more effective, biocompatible and bio-functional materials. In this sense, HA and its derivatives have been positioned as one of the most suitable and widely used compounds for biomedical applications. HA, being the main component of the ECM (Fraser et al., 1997), presents unique characteristics for its use in regenerative medicine. It is also involved in a large number of relevant biological functions in the human body, such as wound healing (Li et al., 2018), inflammation (Chan et al., 2015), cell proliferation and migration (Murakami et al., 2018), embryogenesis, morphogenesis (Toole, 1997) and angiogenesis (Silva et al., 2016)

Thanks to its biocompatibility, biodegradability, mucoadhesive and hydrophilic properties, HA has been successfully applied in a broad range of cosmetics, drugs and medical devices. Moreover, changes of HA concentration are associated with many diseases. Consequently, HA concentration has been analysed in blood, body fluids or tissues as a diagnostic marker of diseases such as rheumatoid arthritis (Niki et al., 2012) and liver pathologies (Gudowska et al., 2017).

HA is also used for supplementation of joint fluid (Wu et al., 2017), eye surgery (Durrie et al., 2018), wound healing (Simman et al., 2018), cosmetic regeneration and reconstruction of soft tissues (Geronemus et al., 2017). HA is degraded by hyaluronidase and/or by reactive oxygen/nitrogen species that are generated during tissue inflammation, inflammatory response in sepsis or ischaemia-reperfusion injury (Valachová et al., 2015; Valachová et al., 2016). Therefore, the poor mechanical properties, rapid degradation and clearance in vivo without crosslinking limit HA clinical applications (Wende et al., 2016). Scaffolds for regenerative medicine application should be degraded over the course of tissue regeneration to allow complete repair by the host tissue. Controlling the degradation rate of an HA-based hydrogel is still a challenge for its applications in TE. It is of great interest to cross-link HA into an hydrogel or to modify it chemically for improving mechanical properties and controlling residence time (i.e. controlled degradation, metabolism and clearance). In recent years, HA derivatives, mainly aiming to improve their mechanical properties and reduce biodegradation, have been extensively studied in cell therapy (Smith et al., 2013), drug delivery (Cai et al., 2017) and TE (Seidlits et al., 2011).

The purpose of the present review was to highlight those medical areas in which HA and its derivatives are significantly contributing, including HA medical formulations with stem cells that are currently being tested for several diseases in clinical trials. Additionally, a brief summary of the different HA chemical modifications that expand its biomedical applications are included. More information as to the chemical transformations of HA is included in other 


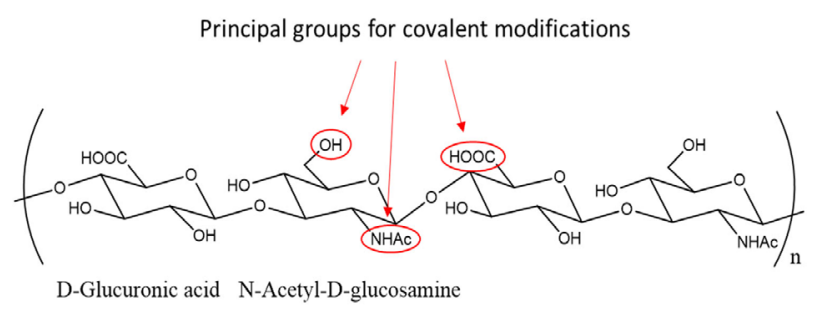

Fig. 1. Molecular structure of HA repeating disaccharide units composed of D-glucuronic acid and N-acetyl-D-glucosamine.

publications (Hemshekhar et al., 2016; Highley et al., 2016; Knopf-Marques et al., 2016; Kuo and Prestwich, 2011; Prestwich, 2011; Schanté et al., 2011).

\section{HA: description and origin}

HA, also called hyaluronan, is one of the ECM glycosaminoglycans that exists as protein-free unbranched long polysaccharide chains with different molecular weights (from $1 \mathrm{kDa}$ up to $8 \mathrm{MDa}$ ) and is exclusively non-sulphated (Barbucci et al., 2000). The backbone is composed of a repeated disaccharide unit of D-GlcA linked $\beta(1 \rightarrow 3)$ to GlcNAc. The disaccharide units are connected by GlcNAc linked $\beta(1 \rightarrow 4)$ to GlcA (Fig. 1) (Furlan et al., 2005; Hargittai and Hargittai, 2008; Liu et al., 2011).

$\mathrm{HA}$ is produced in the cytoplasmic membrane of mammalian cells, amphibians and bacteria by the three HAS membrane enzymes, HAS-1, HAS-2 and HAS-3, which differ in their catalytic activities and molecular weight of the HA synthesised. HAS-1 is responsible for the production of medium to high molecular weight HA (200-2000 kDa), HAS-2 for high molecular weight HA (2000 kDa) and HAS-3 for low molecular weight HA (<300 kDa) (Itano et al., 1999; Lee and Spicer, 2000). HA is continuously extruded through the plasma membrane into the ECM where it provides a hydrophilic viscous medium that facilitates cell motility, proliferation and differentiation (Xu et al., 2012). One of the characteristics of HA is its large capacity to bind water molecules up to 10,000 times its own weight (Laurent, 1992). HA metabolism is regulated by its production through the different HAS and its degradation in the plasma membrane, or in lysosomes, by hyaluronidases to maintain tissue physiological concentrations (Khaldoyanidi et al., 2014). HA is a key component of the ECM, especially abundant in connective tissues and present at high concentration in the synovial fluid of joints, vitreous humour, hyaline cartilage, IVD and umbilical cord (Dicker et al., 2014; Knopf-Marques et al., 2016; Toole, 2004). The major HA receptor is CD44, a cell surface glycoprotein involved in cell-cell and cell-matrix interactions, which is endogenously expressed at low levels in different cell types (Isacke and Yarwood, 2002). Traditionally, HA has been extracted from rooster comb-like animal tissues; however, HA is also produced by bacterial fermentation, mainly using Streptococcus zooepidemicus, a natural manufacturer of HA (de Oliveira et al., 2016; Liu et al., 2011).

\section{HA-derived-biomaterials}

Thanks to its high molecular weight and hydrophilic nature, the polysaccharidic structure of HA can form viscous water solutions that have many interesting uses in biomedical applications, mainly as a carrier of biological components, such as cells (Kim et al., 2017; Prestwich, 2011). Nevertheless, these solutions are not designed to withstand time since, in biological media, HA is easily degraded and the diluted solutions lack sufficient mechanical strength to be self-supporting in a particular location over prolonged time ( $\mathrm{Xu}$ et al., 2012). As such, HA has been subjected to different chemical modifications aimed at expanding its biomedical uses (Prestwich et al., 1998; Schanté et al., 2011; Volpi et al., 2009). Synthetic transformation has focused on increasing its molecular weight to generate novel HA derivatives able to produce a more viscous solution or even gels that can stay longer in the body and have a therapeutic effect. The objective is to modulate the material according to a specific application without compromising its biocompatibility, biodegradability, ability to interact with cells and other living tissue, etc.. In this sense, chemical modifications have been focused on increasing its mechanical strength and/ or improving cell interactions. With respect to increasing HA mechanical strength, two different strategies have been applied. The first one implies the development of cross-linkable HA derivatives through the introduction in the backbone of functional groups able to covalently inter-connect HA polymer chains (Collins and Birkinshaw, 2008). Such modification leads to a cross-linked HA derivative with higher molecular weight and lower solubility that, in the presence of water, forms a self-supported hydrogel (chemical hydrogel) where its rigidity or mechanical strength can be regulated by the degree of cross-linking (Kim et al., 2017). Alternatively, the solubility of HA can also be reduced by introduction of hydrophobic groups in its structure. The nature of these hydrophobic groups and the degree of HA functionalisation are important for the formation of amphipathic structures that tend to form aggregates in the presence of water, generating physical hydrogels (Dicker et al., 2014). Either, hydrophobised or crosslinkable HA derivatives exhibit higher resistance to biodegradation and can be used for cell culture (Aulin et al., 2011), viscosupplementation (Adams et al., 1995) and as vehicle for in vivo cell (Smith et al., 2013) and drug delivery (Cai et al., 2017).

The chemical structure of HA has three potential functional groups that can be easily modified by covalent reaction (Fig. 1): the carboxylic acid of the 
GlcA unit, the primary hydroxyl group of the GlcNAc - although the secondary hydroxyl groups can also be reactive - and the amine group of GlcNAc formed after a deacetylation reaction (Fakhari and Berkland, 2013). The hydroxyl groups can be chemically modified by formation of an ether or ester linkage, while the carboxyl and amine groups can form new ester and amide bonds (Khunmanee et al., 2017). These HA chemical modifications can also fall into two different categories depending if the material can be further functionalised or not (Prestwich and Kuo, 2008). If the material is an end-product that cannot be further modified in the presence of a biological substrate, it is defined as monolithic. However, if it can form new chemical bonds in the presence of a biological substrate it is defined as living. These living HA derivatives can be used in 3D cell cultures and for in vivo cell delivery (Prestwich, 2007). Nevertheless, precautions are required to ensure that all the chemical reactions are biologically biocompatible and do not produce toxic by-products in the short or long term.

\section{Monolithic HA derivatives}

Primary strategies to originate cross-linkable HA derivates are based on the direct cross-link between unmodified HA polymer chains by using bifunctional cross-linker reagents able to react with the hydroxyls and the carboxylic acid of the HA backbone (Burdick and Prestwich, 2011). This protocol uses reaction conditions and reagents incompatible with the presence of cells and, therefore, used to originate monolithic HA derivates (Prestwich, 2011) (Fig. 2). For example, under strong basic conditions, hydroxyl groups can also react with divinylsulphone and different epoxides, such as bisglycidylepoxides (DEO, BDDE) and epichlorohydrin, to form ether linkages more stable to hydrolysis (Wende et al., 2016). Additionally, HA can also react with glutaraldehyde in an acid medium to originate acetal or hemiacetal linkages (Khunmanee et al., 2017). In this sense, Zhang et al. (2012) developed a composite HA-agarose material using epichlorohydrin as a cross-linker. One of the advantages of this material is that its degradation rates can be controlled. In a similar way, Kim et al. (2012) improved the mechanical, degradation and biological response of an HA-collagen composite hydrogel for cartilage regeneration using ethyleneglycoldiglycidyl ether as crosslinker agent. With the objective of reducing HA degradation rates and modulate hydrogel pore sizes, Collins and Birkinshaw (2011) studied a series of HA scaffolds obtained by simply solution gelling using glutaraldehyde, EX 810, EDC with LME and divinylsulphone as cross-linker agents. Results show that a suitable soft tissue HA scaffold is obtained with the combination of EDC and LME (Collins and Birkinshaw, 2011). Lai (2014) studied the amount of divinylsulphone covalently incorporated into the HA structure and its relationship with mechanical stability and resistance against enzymatic degradation of the resulting hydrogels. Its cytocompatibility as a matrix

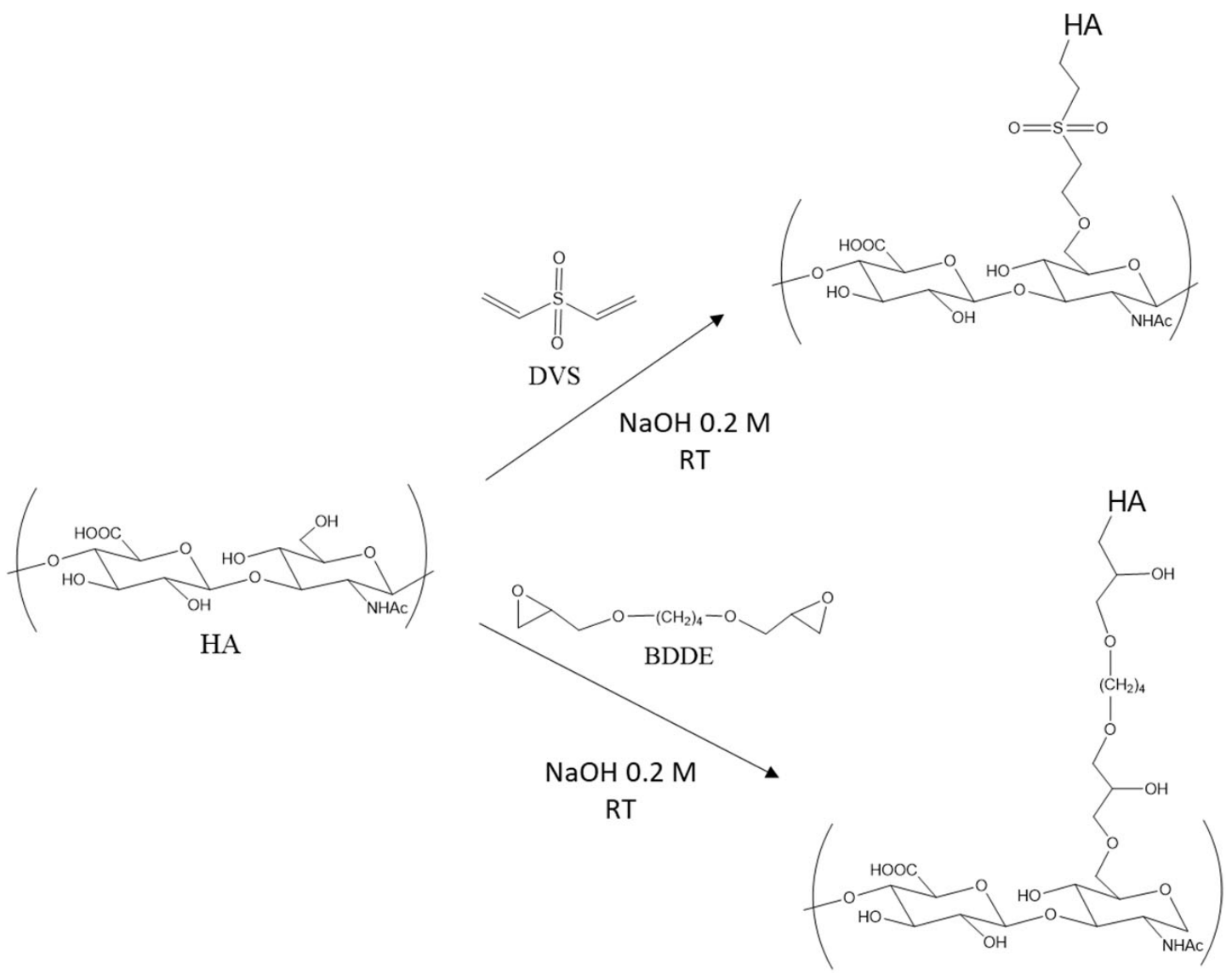

Fig. 2. Traditional monolithic cross-linked transformation of HA with DVS and BDDE. 
for the growth of retinal pigment epithelial cells was also evaluated (Lai, 2014).

A direct cross-linking reaction between HA polymer chains can also be performed with carbodiimides, usually, EDC. The reaction proceeds through activation of the carboxylic acid by EDC to give acylisourea active ester that reacts with nearby hydroxyls generating intermolecular cross-links (Fig. 3 ). This reaction proceeds under mild conditions at neutral $\mathrm{pH}$ and it is compatible with biological macromolecules that can be easily degraded. HA is cross-linked with collagen to enhance its mechanical stability and to improve its biological compatibility (Davidenko et al., 2010; Wang and Spector, 2009). These scaffolds promote angiogenesis (Perng et al., 2011); in addition, the biological performance of HA-gelatine scaffolds of tuneable porosity was studied in the presence of L929 fibroblasts, showing no cytotoxicity (Zhang et al., 2011a). Films composed of HA-carboxymethylcellulose (Seprafilm ${ }^{\circledR}$, SanofiAventis U.S. LLC, Bridgewater, NJ, USA) used as adhesion barrier mainly for abdominal or pelvic laparotomy are chemically produced by EDC crosslinking reaction (Schneider et al., 2007).

\section{Living HA derivatives}

More recently, the focus has been centred on the development of HA derivatives able to form hydrogels in the presence of cells under mild conditions. These materials offer the advantages of originating 3D cell constructs for TE or cell delivery (Ruel-Gariépy and Leroux, 2004). Normally, HA is chemically modified to originate a derivative that can generate the hydrogel in a biological environment by a cross-linking reaction that proceeds under physiological conditions without generating any toxic by-products (Khunmanee et al., 2017). One of the first examples is the coupling of HA with adipic dihydrazine. The reaction proceeds under mild conditions to originate an HA hydrazone derivative stable under physiological conditions that can easily react with aldehyde crosslinking agents through its hydrazine group in the presence of cells (Prestwich et al., 1998; Zhang et al., 2010) (Fig. 4). These HA hydrazone derivatives were coupled with different aldehydes, such as poly(ethylene) glycol aldehyde (Kirker et al., 2002) and genipin (Zhang et al., 2010) to originate materials suitable for TE applications.

Thiol chemistry based on the formation of disulphide bonds or nucleophilic attachment of thiol groups under mild conditions is also compatible with physiological conditions. Shu et al. (2002; 2006) developed an HA derivative using hydrazide reagents containing a disulphide bond. After cleavage of the disulphide bond and the formation of thiol groups, slow formation of crosslinks in the presence of air takes place (Fig. 5).

Gramlich et al. (2013) described the functionalisation of the HA with norbonene groups. This derivative can cross-link under mild conditions by a thiol-ene reaction to produce hydrogels with controllable mechanical properties. HA hydrogels that are formed by an enzymatic reaction were also developed by Kurisawa et al. (2005). HA functionalised with tyramide can rapidly form a hydrogen in the presence of $\mathrm{H}_{2} \mathrm{O}_{2}$ and horseradish peroxidase. This protocol is biocompatible and useful for various applications (Kurisawa et al., 2005; Wang et al., 2010). Huisgen azide-alkyne 1,3-dipolar cycloaddition, known as click chemistry has also been studied for this purpose. Huerta-Angeles et al. (2012) described the synthesis of HA derivatives having an azide and alkyne groups. In the presence of $\mathrm{Cu}(\mathrm{I})$ catalyst the reaction proceeds under physiological conditions to originate the gel. Nevertheless, the presence of the metallic catalyst can introduce toxicity to the environment (Crescenzi et al., 2007).

\section{Hydrophobic HA derivatives}

To originate mechanically stable hydrogels, HA has been modified with the intention of increasing its hydrophobicity. Examples of these types of

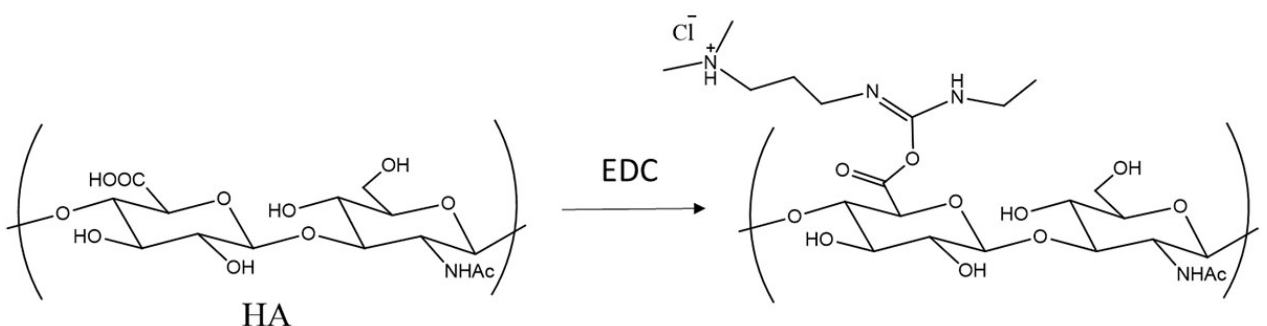

HA

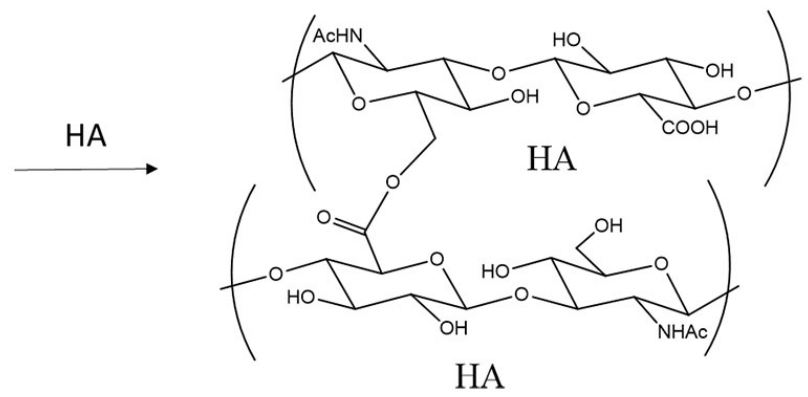

Fig. 3. Cross-linked HA through activation of the carboxylic acid mediated by EDC. 


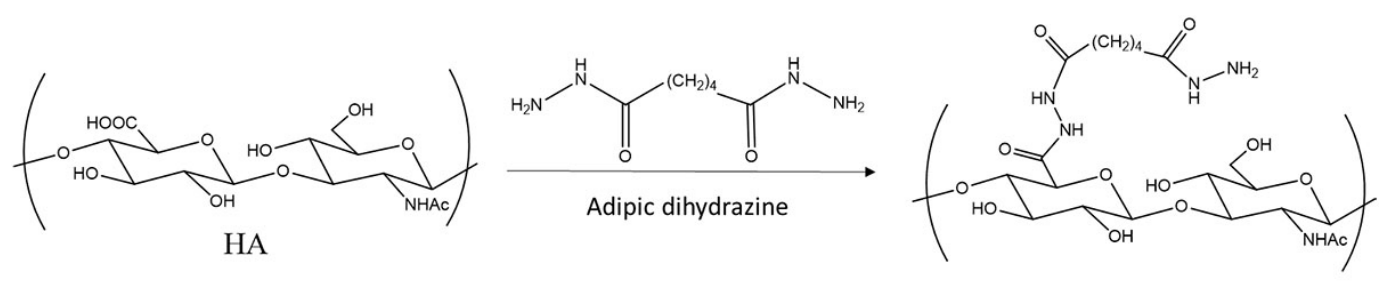

HA hydrazone stable derivative

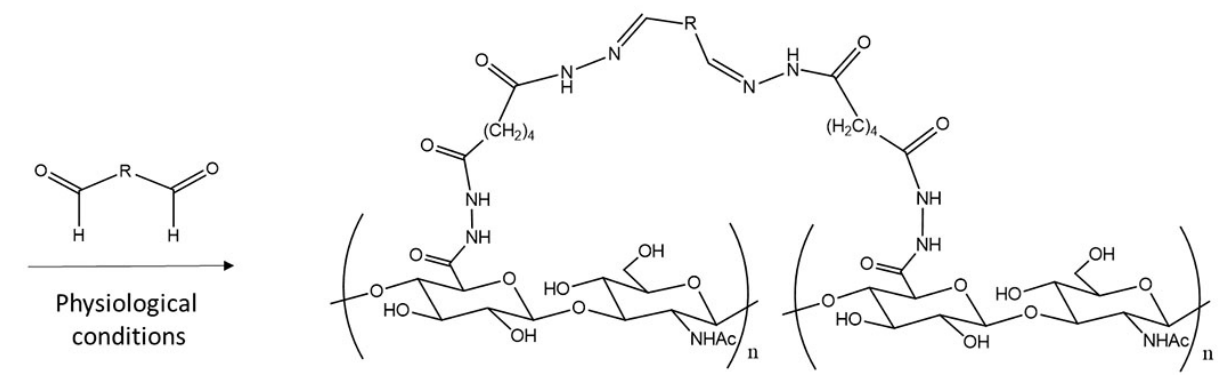

Fig. 4. HA hydrazone derivative that allows cross-linking reactions under physiological conditions.

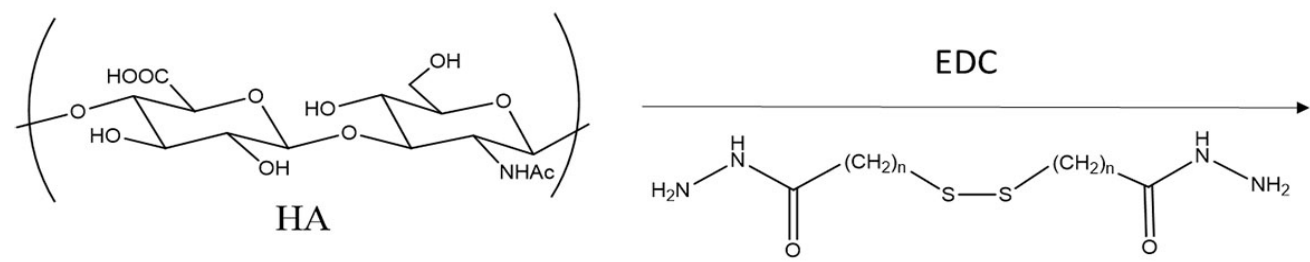<smiles>CCCCCCCCCCCC(=O)NNC(=O)CSCC(=O)NNC(=O)O</smiles>

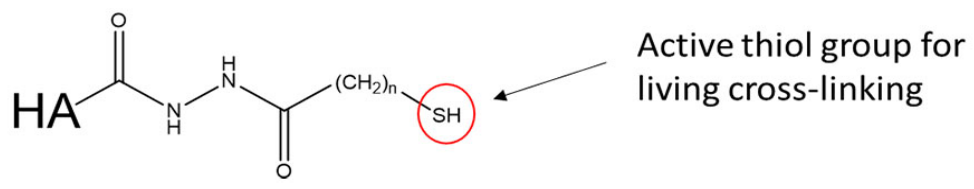

Fig. 5. HA derivative modified with thiol groups for disulphide or thiol-ene cross-linking reaction under physiological conditions.

derivatives are $\mathrm{HYAFF}^{\circledR}($ Haemo Pharma GmbH, Hornstein, Austria) biomaterials that are the result of a partial esterification of HA carboxylates to benzylesters (Benedetti et al., 1993) (Fig. 6). The degree of esterification modifies the physicochemical properties of these materials making them adequate for different applications. These hyaluronan esters can be easily manipulated to produce membranes and fibres, lyophilised to obtain porous materials or processed to produce microspheres (Mano et al., 2007). When the degree of esterification is high, these materials are insoluble in water and are used, in solid form, as scaffolds for the growth of human fibroblasts, chondrocytes and bone-marrow-derived MSCs for repair of cartilage and bone defects (Caravaggi et al., 2003; Lisignoli et al., 2003). Additionally, HYAFF ${ }^{\circledR}$ biomaterials in combination with PCL are excellent biomaterials for the in vivo regeneration of sheep meniscal tissue, where the implants remain in position and show excellent tissue ingrowth (Chiari et al., 2006). Another example commercially available is $\mathrm{HYADD}^{\circledR} 4$ (Fidia Pharma USA, Parsippany, NJ, USA), derived from the partial amidation of HA with hexadecylamine. This derivative forms a 

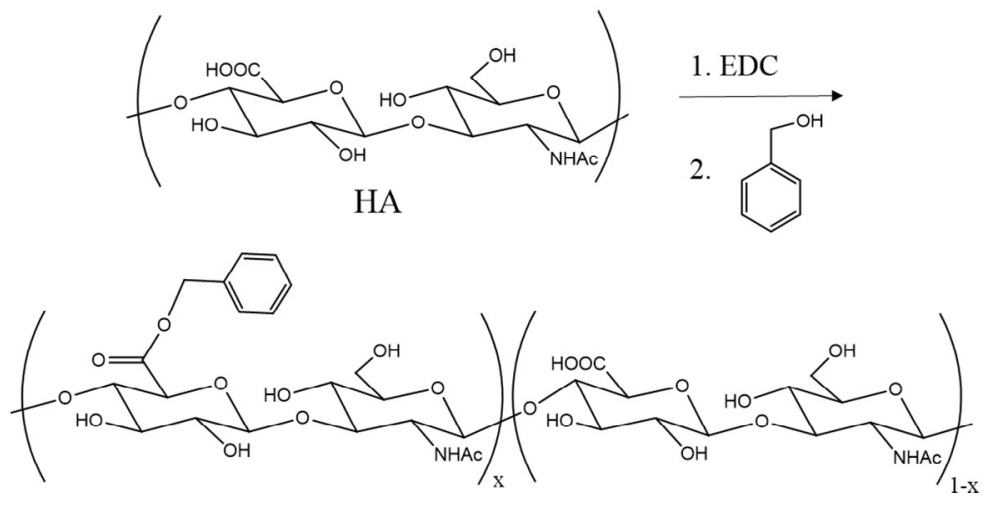

Fig. 6. Partial esterification of HA with benzyl alcohol to originate HYAFF ${ }^{\circledR}$ derivatives.

viscoelastic hydrogel that shows an enhancement of intra-articular residence time (Mainil-Varlet et al., 2013; Priano, 2017).

\section{Improving cell interactions of HA derivatives}

HA has been covalently modified by the addition of biological relevant molecules with the objective of mimicking the native tissue environment and achieving a controlled and tuneable cell response (Lam et al., 2014; Mehra et al., 2006; Zhang et al., 2011b). Additionally, the coupling of ECM proteins also permits the entrapment of antibodies and small molecules within the HA hydrogel, improving its role as an in vivo carrier. In this context, in order to obtain HA materials with cell-attachment properties, HA was modified with cell adhesion motifs, such as short RGD peptides (Shu et al., 2004), and ECM proteins, such as collagen (Mehra et al., 2006), laminin (Hou et al., 2005) and fibronectin (Brown et al., 2011). Camci-Unal et al. (2010) developed a CD34 antibody immobilised on an HA hydrogel for selectively captured and spread EPCs. The results show that these materials can potentially be used to enhance the biocompatibility of implants such as artificial heart valves. Kisiel et al. (2013) developed an HA hydrogel modified with a stabilised fibronectin fragment containing the major integrin-binding domain to improve MSC attachment and spreading. The in vivo delivery of this HA hydrogel derivative containing the rhBMP-2 growth factor results in a significant increase in bone formation and a better organisation of collagen fibres as compared to the non-functionalised HA hydrogel (Kisiel et al., 2013). Likewise, the adhesion of glycosaminoglycans such as heparin and chondroitin sulphate enables the entrapment of growth factors, which also makes HA suitable for cell culture and differentiation (Ghosh et al., 2006; Hosack et al., 2008; Kontturi et al., 2014; Lu et al., 2013; Schanté et al., 2011). Following this strategy, $\mathrm{Xu}$ et al. (2011) synthesised a heparin-decorated HA hydrogel that can bind rhBMP-2 specifically. The results show that the controlled release of the growth factor, in combination with the inductive role of HA in chondrogenesis, leads to efficient in vitro differentiation of murine MSCs.
Additionally to the chemical modifications of HA derivatives, there are different processing and fabrication techniques for the development of structurally tuneable and mechanically suitable HA-based materials. Although HA is mainly used as an injectable hydrogel, cross-linked HA scaffolds can be produced by phase-separation, supercritical fluid technology, porogen leaching, freeze-drying or emulsion techniques, whereas fibrous and nanofibrous structures are mainly created by electrospinning (Ekaputra et al., 2008; Knopf-Marques et al., 2016). In addition to the internal architecture patterning obtained by these techniques, geometry and spatial resolution parameters can be customised by other fabrication strategies, such as centrifugal casting (Mironov et al., 2005), scaffold templating (Ortuño-Lizarán et al., 2016), lithography (Takahashi et al., 2009) or 3D printing (Skardal et al., 2010). Recently, 3D bioprinting has gained significant attention since it allows the creation of scaffolds with precise deposition of cells, biomaterials and bioactive molecules (referred to as bioinks) in a spatial location in order to mimic the native tissue anatomy (Khalil and Sun, 2009). The ease of modifying the HA backbone with functional groups, such as hydrophobic moieties or cross-linkable groups, enables obtaining printable hydrogels (Kesti et al., 2015; Loebel et al., 2017). Therefore, thanks to the addition of HA, the bioink viscosity can be increased to allow for continuous extrusion of hydrogel strands (Murphy et al., 2018). The most recent attempt is by Loebel et al. (2017), who developed a self-assembling HA hydrogel based on GH hydrophobic interactions of conjugated groups, Ad (guest) and CD (host). The GH hydrogel is composed of HA as the polymer backbone, which is modified with either the host molecule (CD-HA) or the complementary guest molecule (Ad-HA). The supramolecular GH associations disassemble when ejected through a syringe (shear-thinning) and reassemble within seconds (self-healing) upon cessation of shear (Loebel et al., 2017).

Other strategies consisting of adding gelling agents, both natural and/or synthetic, have also made possible the production of printable HA-based hydrogels (Derakhshanfar et al., 2018; Thomas and 
Willerth, 2017). An example is the use of crosslinking chemistries or gelling components, such as gelatine, to obtain HA bioinks with tuneable mechanical properties that match the tissue of interest physical parameter profiles. Accordingly, Skardal et al. (2010) printed HA-gelatine hydrogels through a syringe needle into robust structures, followed by a second photo-cross-linking step to create a bioprinted tubular construct with cells. After the process of bioprinting and culture, these cells maintain their viability and gradually remodel the synthetic matrix to create a natural ECM (Skardal et al., 2010). Other combinations such as methacrylated gelatine and methacrylated HA modified with hydroxyapatite particles have been prepared for the development of a bioink for bone tissue engineering. This bioink demonstrates its suitability for the buildup of relevant $3 \mathrm{D}$ geometries with microextrusion bioprinting and a significant positive effect on bone matrix development after $28 \mathrm{~d}$ in culture (Wenz et al., 2017). Porous constructs through layer-bylayer deposition of cell-laden material based on HA and hydroxyethylmethacrylate derivatised dextran or atelocollagen have been evaluated for cell viability of encapsulated chondrocytes and human MSCs showing excellent cytocompatibility (Pescosolido et al., 2011; Shim et al., 2016). However, in some cases, the HA bioink is reinforced by double printing with a thermoplastic polymer, such as PCL (Mouser et al., 2017; Shim et al., 2016; Stichler et al., 2017) or PLA (Souness et al., 2018). Park et al. (2011) developed scaffolds of HA grafted to PLGA incorporating rhBMP-2 by SFF. Results show the in vitro enhancement of osteoblast cell growth and high gene-expression levels of alkaline phosphatase and osteocalcin. Moreover, scaffolds implanted into calvarial bone defects of rats reveal effective bone regeneration (Park et al., 2011). Efforts have also been made to simulate the biochemical profile of the scaffold and optimise the bioactivity of the bioink by mixing HA derivatives with ECM components and tissue-specific growth factors, obtaining a more effective tissue regeneration (Shim et al., 2016; Skardal et al., 2015).

\section{Therapeutic applications of HA, including cell therapy}

The success of a cell therapy relies on identifying an appropriate cell source as well as a strategy to maintain and localise the cells in the desired area (López-Ruiz et al., 2016). In this context, stem cells and tissue-specific cells were investigated as suitable cell sources for the repair of different kinds of tissues (Bardelli and Moccetti, 2017). However, current cell therapy practice is inefficient since therapeutic cells are less integrated into the tissue (Lebaschi et al., 2017). To improve cell engraftment and survival after transplantation, new compounds have been proposed as injectable and biological vehicles for delivery. One of these new vehicles is HyStem ${ }^{\circledR}$ (BioTime, Inc., Alameda, CA, USA), a HA-based material approved for cell therapy that is used in combination with stem cells (Prestwich et al., 2012). HyStem ${ }^{\circledR}$ can form a hydrogel in the presence of cells, using a HA living derivative. The cross-linking reaction is mediated by a thiol-ene reaction between the reactive thiol groups of a thiolated HA and a denatured collagen (Gelin-S, BioTime, Inc.) that reacts with polyethylene glycol diacrylate (Extralink, BioTime, Inc.) cross-linker reagent. Smith et al. (2013), in an in vivo study using a mouse model of $\mathrm{MI}$, observed that an injection of HyStem ${ }^{\circledR}$ containing CDCs dramatically increases cell retention $24 \mathrm{~h}$ after delivery when compared with cells in PBS. Even in long-term cell engraftment (3 weeks after delivery), a significant retention is observed. Also, improvements in left ventricular ejection fraction and addition of viable myocardial mass are demonstrated (Smith et al., 2013). Murugan Girija et al. (2018) demonstrated that the expression of keratinocyte-specific markers by human predifferentiated gingival MSCs is higher when the cells are encapsulated in HyStem ${ }^{\circledR}$ as compared with 2D culture, showing that HA-based hydrogels provide a 3D environment to enhance differentiation.

Given that HA is a major constituent of the eye, HA hydrogels also provide ideal viscous solutions for retinal repair in ocular surgery (Durrie et al., 2018). HA-based hydrogels are also studied as an injectable delivery system of mouse RPCs into subretinal space. Transplantation of these HA hydrogels causes very little disruption to the host retinal architecture while providing a unique microenvironment for selfrenewal and differentiation of RPCs (Liu et al., 2013). Liu et al. (2013) studied different systems with varying ratios of HyStem ${ }^{\circledR}$ components vs. cells medium and amount of Extralink with the purpose of modulating the mechanics and degradation time of the hydrogel matrix. In this sense, hydrogels with $40 \%$ and $20 \%$ HyStem ${ }^{\circledR}$ volume effectively support self-renewal of RPCs, while the $80 \%$ HyStem $^{\circledR}$ does not support the growth and survival of mouse RPCs probably due its higher concentration, which would substantially block nutrients and oxygen supply (Liu et al., 2013). These cross-linkable HA derivatives degrade over a period of 3 weeks, showing greater stability than a previous blend of HA and methylcellulose (Ballios et al., 2010). However, the bioresorbable hydrogel blend of HAMC is also applied as an injectable hydrogel delivery strategy to promote cell survival and integration of transplanted retinal stem cell-derived rods and NSCs in the retina and brain, respectively, for functional repair (Ballios et al., 2015). The survival effect observed after 3 weeks post-transplantation in HAMC versus saline vehicle is attributed to cellmaterial interactions through the CD44 receptor, since CD44 ${ }^{-/-}$cells do not show increased survival in vivo (Ballios et al., 2015). Also, HA is widely used in cartilage repair to restore the biologic environment of the joint in OA patients. In fact, IA injection of $\mathrm{HA}$ is considered to be a treatment for early OA, 
acting as a lubricant in the joint space in order to reduce pain by reducing the friction of the joint and improving viscoelasticity of the synovial fluid (Campbell et al., 2015; Concoff et al., 2017). There are different commercial preparations based on HA for viscosupplementation by IA injections (Jones et al., 2018). These products differ in their composition, molecular weight, average life in the joint and price (Altman et al., 2016; Estades-Rubio et al., 2017).

Non-surgical IA orthobiologic injectables to treat OA also include PRP, a blood-derived product rich in growth factors. PRP can enhance production of ECM, inhibit inflammation and display beneficial effects on cartilage regeneration (Cengiz et al., 2018; Wu et al., 2011). In a recent study conducted by Filardo et al. (2015), the efficacy of IA injections of highmolecular-weight HA (Hyalubrix ${ }^{\circledR}$, Fidia Pharma USA) versus the use of PRP for the treatment of knee cartilage degenerative lesions and OA was compared. Although preliminary results suggest that PRP injections might offer a clinical improvement, both treatments decrease the pain in knee of OA patients but the data are not statistically significant (Filardo et al., 2015). Recent studies still disagree on which of the two strategies is most beneficial for patients (Dai et al., 2017; Ye et al., 2018; Zhang et al., 2018). Moreover, others have proposed the development of a new formulation combining HA and PRP to achieve a more effective treatment for OA (Andia and Abate, 2014; Chen et al., 2014; Lana et al., 2016; Russo et al., 2016). This combination is based on the fact that, on one hand, PRP could provide growth factors that may modify gene expression of OA chondrocytes and enhance the anabolic activity of chondrocytes while, on the other hand, HA may reduce pain and provide the viscosupplementation needed for OA treatment. Russo et al. (2016) studied the combination of PRP with different HA formulations (Sinovial ${ }^{\circledR} 0.8 \%$; Sinovial Forte ${ }^{\circledR} 1.6 \%$; Sinovial HL ${ }^{\circledR} 3.2 \%$; Hyalubrix ${ }^{\circledR}$ $1.5 \%$, Fidia Pharma USA) in order to evaluate their in vitro biological effect on osteoarthritic chondrocytes and which HA formulations are more suitable to use in combination with PRP. Their results demonstrate that viscosupplements containing low HA concentration are not indicated for combination with PRP, as the viscoelastic properties are lost. In all cases, the chondrocyte GAG content and proliferation rate are higher in media containing PRP and HA formulations than in media containing only HA formulations. Interestingly, although Sinovial Forte $^{\circledR}$, Sinovial HL ${ }^{\circledR}$ and Hyalubrix ${ }^{\circledR}$ present the same rheological profile, Sinovial $\mathrm{HL}^{\circledR}$ is superior in stimulating GAG production (Russo et al., 2016).

In addition to HA and PRP, a third-generation of IA injection therapy using BMC has emerged with the aim of retarding the progressive destruction of

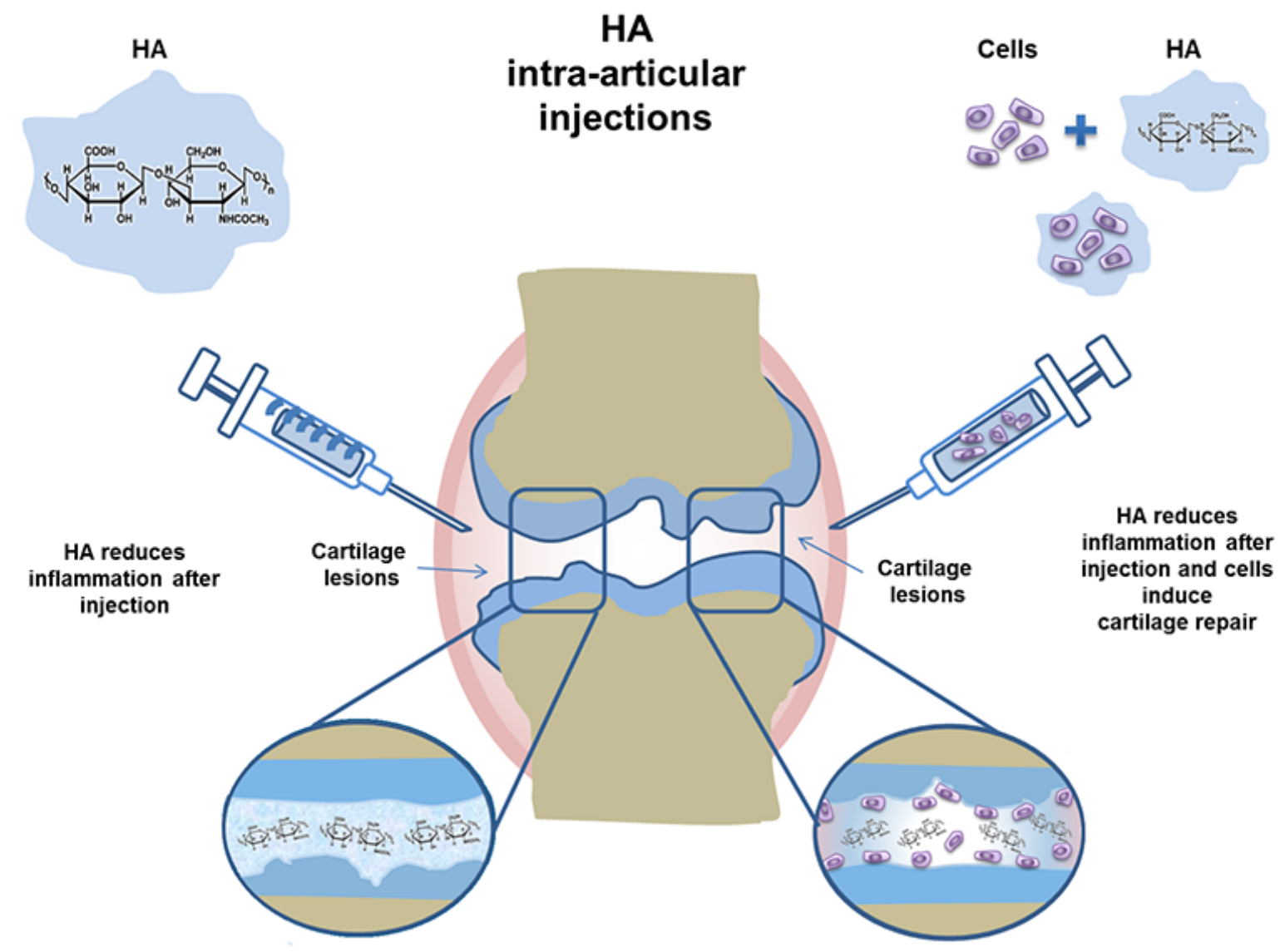

Fig. 7. Intra-articular injections of HA. Intra-articular injections of HA are widely used as a lubricant in the joint space for the treatment of knee OA pain. In recent years, stem cell injections have been used in combination with HA for cartilage tissue regeneration. 
cartilage (Sampson et al., 2013). The development of articular stem cell therapies is promising, since these cells have the ability for self-renewal and differentiation into osteogenic or chondrogenic lineages (Canadas et al., 2018). HA injection therapies, combined with MSCs from BM, are currently under investigation for bone and cartilage tissue regeneration (Kaleka et al., 2018; Roffi et al., 2018), (Fig. 7). Indeed, BMC injections are used in combination with HA and fibrin, a protein scaffold with the natural ability to change phase from liquid to gel by addition of thrombin (Huh et al., 2016). Therefore, fibrin is used with HA to promote retention of BMC at the injected site, forming a polymer composite within a few minutes after being injected. The mixture injected, following a microfracture procedure, can induce chondrogenesis in vivo and represents a novel strategy for treatment of chondral defects (Huh et al., 2016).

In addition to BM stem cells, recent in vivo studies in small and large animal models have tested hydrogel composites of human UCB-MSCs mixed with $4 \%$ sodium hyaluronate. These formulations show an improvement in the histologic appearance of the repaired articular cartilage tissue, which could represent a stepping stone to future human clinical trials (Ha et al., 2015; Park et al., 2015). Moreover, since stem cells possess the capacity to migrate to the site of injury, HA hydrogels combined with drugs or growth factors were developed in order to guide endogenous stem cells towards a specific site or injured area and to promote the regeneration of the tissue (Jha et al., 2015). The slow release of rSDF- $1 \alpha$ inside of a crosslinked HA hydrogel significantly increases BMC chemotaxis in vitro and improves cell engraftment and BMC homing to the remodelling myocardium better than the delivery of rSDF- $1 \alpha$ alone following experimental MI (Purcell et al., 2012). The engineered HA hydrogel is formed in situ through photoinitiated radical polymerisation using a HA derivative previously esterified with HEMA. The hydrolysis of the ester bonds between the HA backbone and the methacrylate groups allows slow degradation of the hydrogel and subsequent release of rSDF- $1 \alpha$ (Purcell et al., 2012). In a different study, HyStem ${ }^{\circledR}-\mathrm{C}$ hydrogel is used to load BDNF, which is delivered in the brain following distal middle cerebral artery occlusion. 6 to 8 weeks after implantation, improved sensorimotor function is observed in treated rats and infarct volume is reduced, suggesting that targeted intracerebral delivery of BDNF using this hydrogel may mitigate ischaemic brain injury and restore functional deficits by reducing neuroinflammation (Ravina et al., 2018).

Another appreciated function of HA comprises its use as a system for molecule delivery (Fig. 8). CD44, is highly expressed in articular cells, particularly chondrocytes (Ishida et al., 1997); therefore, based on the binding property of CD44 with its ligand HA, the development of HA-coated nanoparticles for drug delivery has been investigated. Nanoparticles

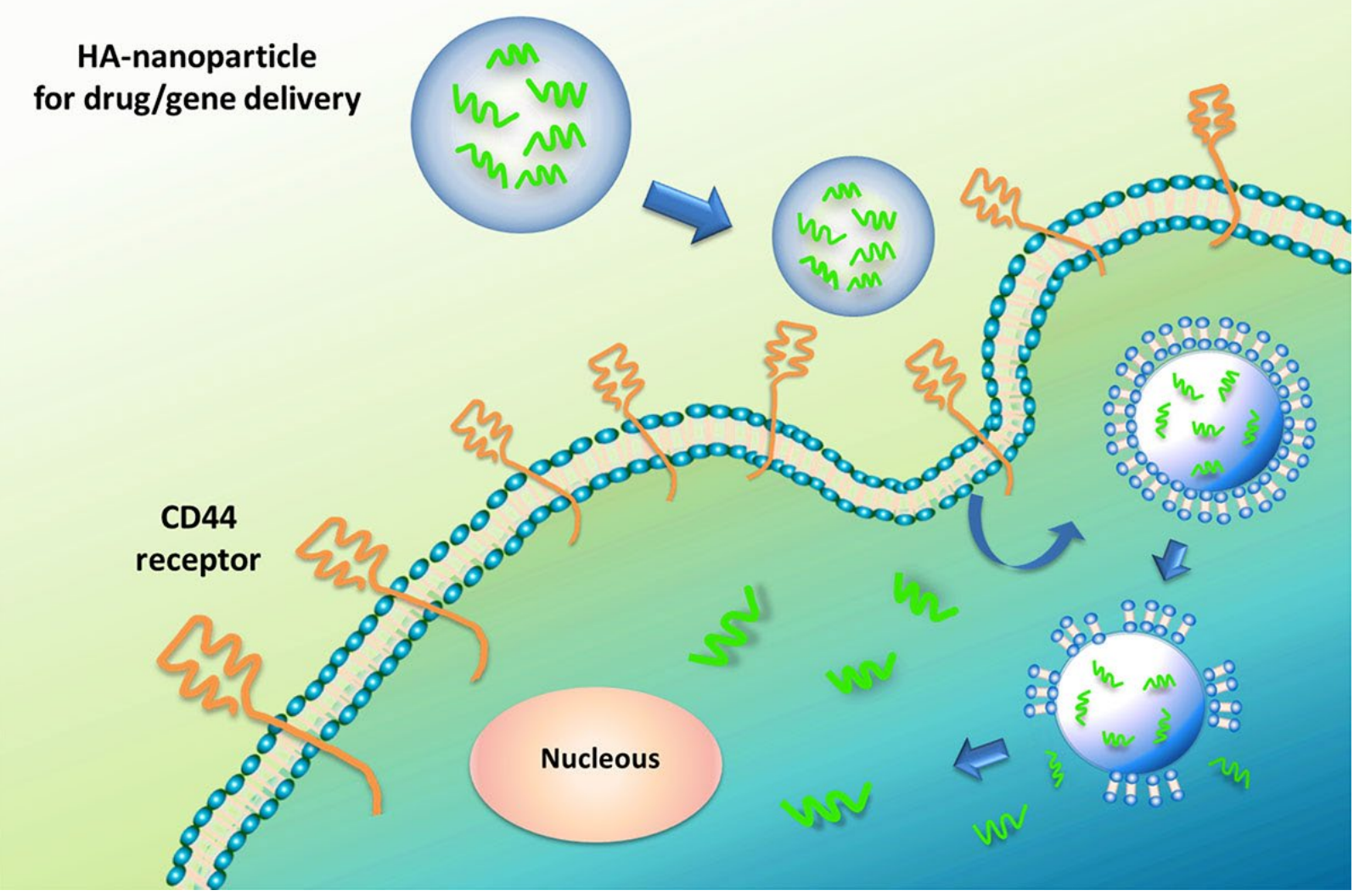

Fig. 8. HA-modified nanoparticles are easily internalised by $\mathrm{CD}_{4} 4^{+}$cell. The $\mathrm{CD} 44$ receptor present on the surface of articular cells, particularly of chondrocytes, mediates internalisation of the nanoparticles that can be loaded with therapeutics agents or complexed with genes for regenerative medicine strategies. 
of several synthetic polymers, such as PLA or PLGA, are covered with HA in order to allow for sustained drug delivery in the vicinity of the joint and to achieve high drug concentrations at the site of action for the treatment of arthritis and/or OA (Laroui et al., 2007; Zille et al., 2010). Moreover, the potential role for HA in gene therapy strategies has been tested by the formulation of HA nanoparticles as delivery systems for plasmid DNA. For example, hybrid HA/ chitosan nanoparticles were developed as novel nonviral gene delivery vectors capable of transferring exogenous genes into primary chondrocytes for the treatment of joint diseases (Lu et al., 2011).
Indeed, higher chondrocyte transfection efficiency of nanoparticles containing $\mathrm{HA} /$ chitosan and pDNA encoding TGF- $\beta 1$ is observed as compared to the same nanoparticles without HA (Lu et al., 2013). In addition, the formulation of a novel HA hydrogel as a delivery system for the controlled release of gapmer antisense oligonucleotides for unassisted cellular entry and subsequent gene silencing activity was also investigated for cartilage repair and interruption of damage progression by Cai et al. (2017).

HA was also studied in the treatment of different pathologies in which the immune system is deregulated, such as DM, RA and Sjögren

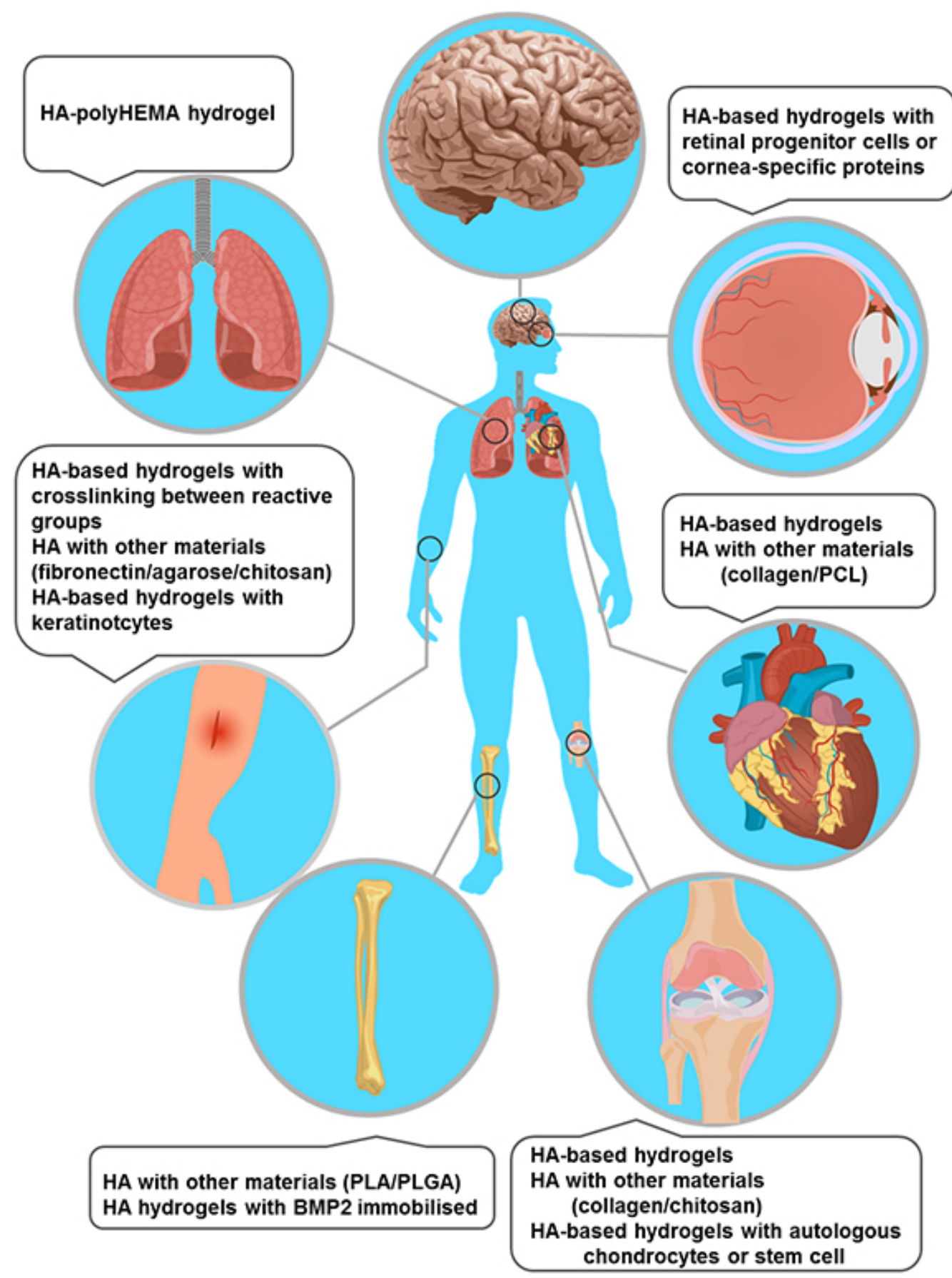

Fig. 9. Therapeutic applications of HA-based scaffolds in organ-specific TE and regenerative medicine. HA-based scaffolds are a key component for biomedicine applications such as the healing and regeneration of cartilage, bone, skin, nervous, cardiac and lung tissue and eye surgery. 
syndrome, among others. CD44 is expressed by numerous immune cell types (lymphocytes, neutrophils, macrophages, natural kill cells, etc.) and the interaction of HA with CD44 favours the activation and migration of these cells towards the inflamed injury, with HA interacting with cytokines and modulating the immune responses (Zamboni et al., 2018; Zamboni and Collins, 2017). Nakamura et al. (2004) showed, in a mouse liver injury model, that high molecular weight HA has intrinsic antiinflammatory properties since HA-CD44 binding can inhibit the production of proinflammatory cytokines. Rho et al. (2018) showed that HA-based nanoparticles can suppress the inflammation of the adipose tissue in type $2 \mathrm{DM}$ because of a decrease in both macrophages and proinflammatory cytokines. In addition, these nanoparticles can inhibit the domain-containing protein 3 inflammasome activity, causing an improvement in insulin sensitivity and normalised blood glucose levels (Rho et al., 2018). $\mathrm{RA}$ is a chronic autoimmune disorder that results in systemic autoimmune destruction of bone and cartilage. In the treatment of the pathology, HA administered together with solid lipid nanoparticles can improve the vehiculation of different drugs (i.e. glucocorticoids) to inflammatory cells (through binding to $\mathrm{CD} 44^{+}$cells), facilitating the selective release of these drugs in inflamed tissues (Zhou et al., 2018). Dry eye disease is the main clinical manifestation of Sjögren syndrome, a chronic inflammatory disease with an autoimmune basis (Stefanski et al., 2017). HA is administered as a substitute for tears and it acts on the ocular surface, increasing its hydrophilicity and density and reducing the surface tension while favouring the contact time on the cornea and, thereby, the hydration of the eye (Cagini et al., 2017).

\section{Applications in TE}

Another promising area of regenerative medicine in which HA is making a significant contribution is TE. In fact, HA-based scaffolds are widely used in the regeneration of tissues such as cartilage, bone, skin, nerve tissue and cardiac tissue (Hemshekhar et al., 2016) (Fig. 9).

\section{Cartilage and bone TE}

There is an increasing interest in the study of HA-based 3D scaffolds for cartilage and bone TE (Bowman et al., 2018). HA has been used for cell encapsulation of hESC-derived chondrogenic cells. Toh et al. (2010) created a cell-engineered cartilage by mixing the cells with $\mathrm{HyStem}^{\circledR}$ matrix. This artificial ECM was investigated in an osteochondral defect rat model showing a complete integration with the adjacent host cartilage, with no evidence of tumorigenicity, and generating an ECM similar to the native cartilage tissue (Toh et al., 2010). The concentration of HA is a determining factor in the production of hyaline cartilage, since it is directly related to expression of chondrogenic genes, production of GAGs and suppression of fibrocartilage production (Zhu et al., 2017). Erickson et al., (2012) established that lower concentrations (1\% w/vol) of crosslinked HA hydrogels increase MSC seeding density more than hydrogels at $3 \%$ or $5 \% \mathrm{w} /$ vol concentrations. These hydrogels formed by a photocrosslink reaction of a MeHA derivative are highly appropriate to form ECM and to reproduce the native cartilage tissue properties (Erickson et al., 2012). An additional advantage of HA for cartilage regeneration is related to its release ability. As shown by Deng et al. (2019), the incorporation of HA to PLA/ PEG/PLA hydrogels favours a controlled release of TGF- $\beta 3$, which improves chondrogenesis both in vitro and in vivo.

For bone regeneration, several scaffolds have been created by the combination of HA with other polymers with the aim of providing good mechanical properties and improving degradation rates. Antunes et al. (2010) developed a hybrid scaffold that shows great promise for bone tissue applications. HA has been used to coat scaffolds produced from PLA and to enhance the bio-compatibility and biological cell response, joining the best properties of each material. 3D PLA porous hybrid scaffolds are coated with HA, followed by crosslinking with glutaraldehyde, to produce biomimetic porous scaffolds for cortical bone therapeutic agents. In addition, results derived from using fibroblasts show that these scaffolds allow cell adhesion, growth and proliferation (Antunes et al., 2010). This improvement of mechanical properties can also be achieved thanks to the combination of different natural materials. Combination of HA with nano-hydroxyapatite, chitosan and chondroitin sulphate allows obtaining scaffolds that mimic both the structure and the composition of natural bone, also showing a good biocompatibility ( $\mathrm{Hu}$ et al., 2017). On the other hand, modifications in $\mathrm{HA}$, such as sulphation, can induce differentiation towards osteoblasts and production of a native bone ECM, through synthesis, secretion and/or activity of fibrillary or non-fibrillary ECM components, including proteases and their inhibitors (Schmidt et al., 2018).

\section{Skin TE}

Skin substitutes, including acellular matrices, cellular substitutes and keratinocyte grafts, must meet indispensable characteristics, such as semipermeable barrier, cell adhesion, non-toxic, noninflammatory, non-immunogenic, durable, malleable and biodegradable properties (Nicholas et al., 2016). HA combines such characteristics with the ability to inhibit tissue adhesion and scar tissue formation (Monteiro et al., 2015). Thiolated HA derivatives based on the strategy developed by Shu et al. (2002) can oxidise in air to form disulphide cross-linked HA hydrogels. Following this strategy, commercial thiolated carboxymethyl hyaluronic acid or CMHA-S (Canitr $X^{\circledR}$ Gel; Sentr $X^{\circledR}$, Sentr $X^{\mathrm{TM}}$ Animal Care, Inc., 
Salt Lake City, UT, USA), have been marketed to facilitate and accelerate wound healing in dogs. The healing process in the presence of these materials is slower but at the same time the scar formation is minimised (Hadley et al., 2013).

HA was also combined with decellularised extracellular matrix and human peripheral blood mononuclear cells for skin wound healing, showing regeneration of the epidermis and dermis in the wounds created in nude mice (Kuna et al., 2017). Moreover, HA can be applied in combination with other materials. The incorporation of a photocrosslinkable FN conjugated into HA 3D hydrogel network enhances endothelial cell adhesion and angiogenesis showing great potential in skin TE (Seidlits et al., 2011). Tamer et al. (2018) studied the combination of HA with chitosan - a combination that has positive effects on healing - while incorporating mitochondriallytargeted antioxidant-MitoQ (BioAssay Systems, Hayward, CA, USA) an element that allows to obtain better results, with a faster and more efficient healing, and trigger less inflammation in vivo.

Different examples of commercially available products based on HA or its derivatives can be found. Hyalomatrix ${ }^{\circledR}$ (Anika Therapeutics, Inc., Bedford, England) a non-woven pad made of partially esterified HA (HYAFF ${ }^{\circledR}$ ), is a dermal substitute that acts as a 3D scaffold for cellular invasion and capillary growth. This advanced wound care device is indicated for the treatment of partial to full-thickness post-traumatic, post-surgical or deep-chronic wounds, such as vascular ulcers or diabetic foot ulcers (Gravante et al., 2010). Membranes such as LaserSkin ${ }^{\circledR}$ (Fidia Advanced Biopolymers, Padua, Italy), consisting also of $\mathrm{HYAFF}^{\circledR}$ but with microperforations, are available for treatment of chronic, non-healing wounds, allowing successful treatment when used in combination with autologous or allogenic keratinocytes (Uccioli, 2003).

\section{Nervous TE}

HA is a promising material for brain and neural regeneration since it is widely present in the central nervous system and has the capacity to reduce glial scar formation and allow the penetration of cells, nerve fibres and blood vessels (Kornev et al., 2018). Thus, topical applications of a highly purified sodium hyaluronate formulation (Orthovisc ${ }^{\circledR}$, Anika Therapeutics, Inc.) on rat transected sciatic nerves show a significant reduction in perineural scar thickness while, at the same time, promoting neural regeneration (Özgenel, 2003). HA hydrazone derivatives cross-linked with laminin and ECM protein involved in neuronal development and survival have been evaluated for in vivo brain lesion repair. These hydrogels, once implanted into cortical defects created in rats, form a scaffold that support cell infiltration and angiogenesis and promote neurite extension (Hou et al., 2005).

HA hydrazone derivatives have also been coupled with short cell-adhesive peptides such as RGD and
IKVAV. These derivatives show similar results to those obtained for HA-laminin derivatives, promoting cell migration and axonal growth and regeneration (Cui et al., 2006; Wei et al., 2007). Furthermore, hydrogels made of blends of HA and methylcellulose or collagen I can induce neuronal differentiation of brain-derived neural stem/progenitor cells (Brännvall et al., 2007; Mothe et al., 2013; Valderrábano, 2007).

In designing engineered tissues such as nerve and myocardium, an important consideration is the anisotropic structure to accurately mimic the structure and function of the native electroactive tissue (Kim et al., 2007; Valderrábano, 2007). In this context, there has been increasing attention on engineering biomaterial scaffolds that are electrically conductive. Indeed, several research groups have explored the use of conductive polymers to regulate cellular response, including DNA synthesis, cell adhesion, proliferation, migration and differentiation (Jeong et al., 2008; Park et al., 2014; Shi et al., 2008). Wang et al. (2017a) used HA to improve the bioactivity of the conductive polymer PEDOT, a polythiophene derivative. PEDOT-HA conductive nanoparticles are synthesised by chemical oxidative polymerisation and incorporated into PLLA. PEDOT-HA/PLLA films are cultured with neuron-like pheochromocytoma (PC12) cells showing better cell adhesion, viability and spreading as compared with pure PLLA films. Moreover, increased neurite length under electrical stimulation as opposed to under no electrical stimulation condition is demonstrated. The results indicate that the conductive PEDOT-HA/PLLA films combined with electrical stimulation may be a promising strategy for enhancing nerve regeneration in nerve TE (Wang et al., 2017a).

\section{Cardiac TE}

TEHV were studied with the aim of creating living, non-cytotoxic, mechanically analogous heart valve replacements that can grow and remodel with the patient (Masoumi et al., 2014; Sanz-Garcia et al., 2015). VICs are the most prevalent cell type in aortic heart valves and these cells have been utilised to engineer functional TEHV (Mahler and Butcher, 2011; Masoumi et al., 2014). VICs can enhance ECM production on photopolymerisable hydrogels formed from $2 \%$ MeHA solution, proving that HA can stimulate heart valve tissue formation (Masters et al., 2004). Additionally, scaffold degradation products increase VICs cell viability and induce proliferation and matrix synthesis after 6 weeks in culture (Masters et al., 2005). Hybrid meshes that blend HA with PCL support cell adhesion and proliferation over the entire construct and formation of primitive capillary network (Ekaputra et al., 2011; Eslami et al., 2014). Moreover, acellular HA-based hydrogels reduce stress in the heart wall after MI (Ifkovits et al., 2010). Ifkovits et al. (2010) described how mechanical properties of HA hydrogels are modified through a simple alteration in the number of reactive methacrylate groups on the MeHA polymer: 
$30 \%$ (MeHA low) versus $60 \%$ (MeHA high). The two MeHA formulations exhibit similar degradation and tissue distribution upon injection but have different storage modulus ( $8 \mathrm{kPa}$ versus $\sim 43 \mathrm{kPa}$ ). Moreover, only the higher-modulus (MeHA high) treatment group show a statistically smaller infarct area as compared with the control infarct group when injected into a clinically ovine MI model (Ifkovits et al., 2010). Taken together, these studies indicate that HA matrices represent a good choice to promote cardiovascular regeneration.

\section{Other tissues in TE}

Space-filling HA-based scaffolds provide bulking, prevent adhesions, excessive scar formation or function as bio-adhesives after surgical procedures or injury. Hyaloglide ${ }^{\circledR}$ (Anika Therapeutics, Inc.) is an auto-cross-linked HA derivative that forms a highly viscous gel. About $5 \%$ of the HA carboxyl groups are activated to promote the cross-linking reaction by nucleophilic attack of the GluNAc unit primary hydroxyl groups to form an esterified cross-linked HA (Atzei et al., 2007). This HA derivative, approved for clinical use, shows a reduction of pain and a major recovery of sensitivity after tendon and peripheral nerve surgery (Atzei et al., 2007; Pederzini et al., 2013).

Several studies have opened new avenues towards the use of HA-based scaffolds for TE. Espandar et al. (2012) showed the in vivo growth of human adipose stem cells on HyStem ${ }^{\circledR}$ matrix, with cells surviving and expressing human-cornea specific proteins. For lung tissue regeneration, Radhakumary et al. (2011) developed a copolymer of HA-poly HEMA that is non-cytotoxic to mammalian cells. Further, this copolymer hydrogel supports alveolar cell adhesion and growth and is suitable for the adhesion and proliferation of multiple cell types (Radhakumary et al., 2011). For meniscal regeneration, MSCs in a hyaluronan-collagen scaffold display good healing potential with the development of integrated meniscus-like repair tissue (Murphy et al., 2018). Furthermore, the implantation of eEPCs encapsulated in HyStem ${ }^{\circledR}$ matrix demonstrates improved resistance to toxic insult (adriamycin) in vitro, eEPC mobilisation to injured kidneys and improved renal function (Ratliff et al., 2010).

\section{Clinical applications of HA with cells and tissues}

Cell therapies and TE remain very active areas of research, which have been translated to clinical trials at an extraordinary pace recently (Gálvez-Martín et al., 2017). Currently, from a total of 6,085 clinical trials with stem cells being carried out worldwide, 16 assess the efficacy and safety of stem cells in combination with HA for different therapeutic applications, most of which focus on $\mathrm{OA}$ and cartilage regeneration (Table 1a,b). Moreover, HA viscosupplementation is a popular treatment option in the non-operative management of patients with OA; HA is also used in many studies as an active control to compare the efficacy of stem cell transplantation in many OA treatments (Web ref. 1-6). The increasing use of HA in combination with cells in current clinical trials usually responds to the need of improving delivery methods and enhancing survival and retention of cells in vivo. Randomised controlled trials have been successfully carried out and are currently evaluating an optimal stem cell source, together with HA for therapeutic repair of cartilage tissue. In one of these clinical studies, Saw et al. (2013) transplanted autologous PBSCs in combination with HA into an articular cartilage defect by IA injections after arthroscopic subchondral drilling. This resulted in an improvement of the quality of articular cartilage repair when compared with the same treatment with injections of HA alone (Saw et al., 2013; Web ref. 7). A similar study using PBSCs and HA is currently recruiting patients (Web ref. 8). Attempts to regenerate cartilage have also been made using MSCs originating from the $\mathrm{BM}$. In a recent multicentre randomised clinical trial, IA delivery of increasing doses of BM-MSCs in combination with HA sodium salt (1,500-2,000 kDa; Hyalone ${ }^{\circledR}$, Fidia Farmaceutici S.p.A., Abano Terme, Italy) has been evaluated (Web ref. 9). Both treatments, HA alone or with low-dose BM-MSCs $\left(10 \times 10^{6}\right)$, can reduce pain in the first 6 months; however, patients receiving the high-dose of BM-MSCs $\left(100 \times 10^{6}\right)$ together with HA exhibit an improvement in their perception of pain in their daily activity after 12 months as compared to HA alone (Emadedin et al., 2012). The study demonstrated that the single IA injection of in-vitro-expanded autologous BM-MSC s together with HA is a safe and feasible procedure, which results in a clinical and functional improvement of knee OA (Lamo-Espinosa et al., 2016). Recently, the long-term results of this clinical trial have been published confirming the safety of the procedure and a functional improvement of knee OA after a follow up of 4 years. However, long-term results show no clinical differences between low-dose and high-dose groups and the authors' question if a high dose of cells is needed. Additionally, the control group receiving only HA initially perceives pain reduction and improvement of physical function subscores but these improvements are not sustained after a long-term follow up. In any case, these results support the development of future phase III clinical trial (Lamo-Espinosa et al., 2018). Similarly, another clinical trial aims at determining the efficacy of single IA implantation of autologous BM-MSCs in a high molecular weight injectable HA (Orthovisc ${ }^{\circledR}$, Anika Therapeutics, Inc.) for the treatment of patients with mild to moderate OA: HA is used as an active comparator and the objective is to elucidate if IA implantation of autologous BMSCs in patients with mild to moderate OA can regenerate damaged cartilage (Web ref. 10). In another study,

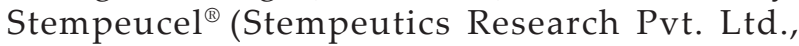
Bangalore, India), which consists of a cryopreserved stem cell product containing allogeneic MSCs 
Table 1a. Clinical trials with HA and stem cells.

\begin{tabular}{|c|c|c|c|c|c|}
\hline NTC number & Phase & Indication & Intervention & Purpose & Cell type \\
\hline NCT01076673 & II & $\begin{array}{l}\text { Articular } \\
\text { cartilage } \\
\text { disorder of } \\
\text { knee }\end{array}$ & IA injections of PBSCs and HA & $\begin{array}{l}\text { To compare articular cartilage } \\
\text { regeneration in patients with } \\
\text { chondral lesions treated by } \\
\text { arthroscopic subchondral drilling } \\
\text { followed by postoperative IA } \\
\text { injections of HA with and } \\
\text { without PBSCs }\end{array}$ & PBSCs \\
\hline NCT02123368 & I/II & OA & $\begin{array}{l}\text { IA injection of BM-MSCs (dose } \\
\text { groups: } 10 \text { and } 100 \text { million cells) } \\
\text { cultured ex vivo followed by an IA } \\
\left.\text { injection of HA (Hyalone }{ }^{\circledR}\right)\end{array}$ & $\begin{array}{l}\text { To determine the safety, } \\
\text { feasibility and effectiveness of IA } \\
\text { administration of different doses } \\
\text { of BM-MSCs in combination } \\
\text { with HA }\end{array}$ & $\begin{array}{c}\text { Autologous } \\
\text { BM-MSCs }\end{array}$ \\
\hline NCT01459640 & II & OA & $\begin{array}{l}\text { Single IA implantation of } \\
\text { BM-MSCs in } 30 \mathrm{mg} / 2 \mathrm{~mL} \text { of HA } \\
\left.\text { (Orthovisc }{ }^{\circledR}\right)\end{array}$ & $\begin{array}{l}\text { To determine the efficacy of IA } \\
\text { implantation of autologous BM- } \\
\text { MSCs for treatment of patients } \\
\text { with mild to moderate OA }\end{array}$ & $\begin{array}{r}\text { Autologous } \\
\text { BM- MSCs }\end{array}$ \\
\hline NCT01453738 & II & Knee OA & $\begin{array}{l}\text { Single IA dose of Stempeucel } \\
\text { (dose groups: } 25,50,75 \text { and } \\
150 \text { million cells) followed by } \\
2 \mathrm{~mL} \text { of HA }(20 \mathrm{mg})\end{array}$ & $\begin{array}{l}\text { To evaluate the safety, potential } \\
\text { efficacy and appropriate dose of } \\
\text { IA administration of Stempeucel }^{\circledR} \\
\text { followed by HA in patients with }^{\text {OA of the knee joint }}\end{array}$ & $\begin{array}{l}\text { Allogeneic } \\
\text { BM-MSCs }\end{array}$ \\
\hline NCT00225095 & $\mathrm{I} / \mathrm{II}$ & $\begin{array}{l}\text { Recovery } \\
\text { following } \\
\text { partial medial } \\
\text { meniscectom }\end{array}$ & $\begin{array}{l}\text { IA injection of Chondrogen }{ }^{\mathrm{TM}} \text {, a } \\
\text { preparation of BM-MSCs (dose } \\
\text { goups: } 50 \text { and } 150 \text { million cells) } \\
\text { suspended in } 2 \mathrm{~mL}(20 \mathrm{mg}) \text { of } \\
\text { sodium hyaluronate, human } \\
\text { serum albumin }(1.2 \%) \text { and } \\
\text { PlasmaLyte A }\end{array}$ & $\begin{array}{l}\text { To determine whether } \\
\text { Chondrogen }{ }^{\mathrm{TM}} \text { is a safe and } \\
\text { effective post-operative } \\
\text { treatment of the knee following } \\
\text { menisectomy }\end{array}$ & $\begin{array}{l}\text { Allogenic } \\
\text { BM-MSCs }\end{array}$ \\
\hline NCT02659215 & $\mathrm{N} / \mathrm{P}$ & $\begin{array}{l}\text { Defect of } \\
\text { articular } \\
\text { cartilage }\end{array}$ & $\begin{array}{l}2 \mathrm{~mL} \text { of BMAC loaded per } \\
\text { Hyalofast }{ }^{\circledR} \text { scaffold (a benzyl ester } \\
\text { of HA) and, then, implanted to } \\
\text { cover the defect }\end{array}$ & $\begin{array}{l}\text { To evaluate the efficiency of } \\
\text { Hyalofast }{ }^{\circledR} \text { together with BMAC, } \\
\text { in a one-step arthroscopic } \\
\text { procedure as compared to } \\
\text { microfracture in the treatment of } \\
\text { symptomatic cartilage } \\
\text { defects of the knee }\end{array}$ & BMAC \\
\hline NCT01088191 & $\mathrm{I} / \mathrm{II}$ & $\begin{array}{l}\text { Anterior } \\
\text { cruciate } \\
\text { ligament } \\
\text { injury, OA }\end{array}$ & $\begin{array}{l}\text { Single injection into the knee } \\
\text { joint of two different single doses } \\
\text { of MSB-CAR001 (mesenchymal } \\
\text { precursor cells, Mesoblast, Ltd) } \\
\text { combined with HA }\end{array}$ & $\begin{array}{l}\text { To evaluate safety and efficacy } \\
\text { of MSB-CAR001 in subjects who } \\
\text { have undergone an anterior } \\
\text { cruciate ligament reconstruction } \\
\text { since short time }\end{array}$ & $\begin{array}{l}\text { Allogeneic } \\
\text { MPCs }\end{array}$ \\
\hline NCT01290367 & II & $\begin{array}{l}\text { Degenerative } \\
\text { disc disease }\end{array}$ & $\begin{array}{l}\text { Injection of MPCs (dose groups: } \\
6 \text { and } 18 \text { million cells) in a HA } \\
\text { carrier into the degenerated } \\
\text { lumbar disc's nucleus pulposus }\end{array}$ & $\begin{array}{l}\text { To compare two doses of } \\
\text { immunoselected, allogeneic } \\
\text { MPCs when combined in a HA } \\
\text { carrier in subjects with chronic } \\
\text { lower back pain due to moderate } \\
\text { degenerative disc disease }\end{array}$ & $\begin{array}{l}\text { Allogeneic } \\
\text { MPCs }\end{array}$ \\
\hline NCT02412735 & III & $\begin{array}{l}\text { Degenerative } \\
\text { disc disease }\end{array}$ & $\begin{array}{c}\text { Injection into the painful IVD of } \\
\text { Rexlemestrocel-L (dose: } 2 \mathrm{~mL} \text { of } \\
6 \text { million cells) alone or combined } \\
\text { with } 1 \% \mathrm{HA}\end{array}$ & $\begin{array}{l}\text { To evaluate the safety and efficacy } \\
\text { of Mesoblast's Rexlemestrocel-L } \\
\text { alone or combined with HA in } \\
\text { subjects with chronic lower } \\
\text { back pain }\end{array}$ & $\begin{array}{l}\text { Allogeneic } \\
\text { MPCs }\end{array}$ \\
\hline
\end{tabular}


Table 1b. Clinical trials with HA and stem cells.

\begin{tabular}{|c|c|c|c|c|c|}
\hline NTC number & Phase & Indication & Intervention & Purpose & Cell type \\
\hline NCT02338271 & I & Lower back pain & $\begin{array}{l}\text { A single injection into the centre } \\
\text { of the nucleus pulposus of } \\
\text { adipose-derived MSCs (dose } \\
\text { group: } 2 \times 10^{7} \text { and } 4 \times 10^{7} \text { cells/ } \\
\text { mL/vial) plus Tissuefill }{ }^{\circledR} \\
1 \mathrm{~mL} / \text { syringe }\end{array}$ & $\begin{array}{c}\text { To evaluate safety and efficacy } \\
\text { of autologous adipose-derived } \\
\text { MSC implantation in chronic } \\
\text { lower back pain patients with } \\
\text { lumbar IVD degeneration }\end{array}$ & $\begin{array}{c}\text { Autologous } \\
\text { adipose- } \\
\text { derived MSCs }\end{array}$ \\
\hline NCT01733186 & $\mathrm{I} / \mathrm{II}$ & $\begin{array}{l}\text { Degeneration of } \\
\text { articular knee } \\
\text { cartilage }\end{array}$ & $\begin{array}{l}\text { Single-dose of } 0.5 \mathrm{~mL} \text { of } \\
\text { Cartistem }{ }^{\circledast}(\mathrm{UCB}-\mathrm{MSCs} \\
\text { combined with sodium } \\
\text { hyaluronate) per } \mathrm{cm}^{2} \text { of } \\
\text { cartilage defect }\end{array}$ & $\begin{array}{l}\text { To determine the safety and } \\
\text { efficacy of Cartistem }{ }^{\circledast} \text { in the } \\
\text { treatment of articular cartilage } \\
\text { defects of the knee as a result of } \\
\text { ageing, trauma or degenerative } \\
\text { diseases }\end{array}$ & UCB-MSCs \\
\hline NCT02755376 & $\mathrm{N} / \mathrm{P}$ & $\begin{array}{c}\text { Injuries of anterior } \\
\text { cruciate ligament }\end{array}$ & $\begin{array}{l}\text { Single-dose of Cartistem }{ }^{\circledR} \\
\text { a combination of human UCB- } \\
\text { MSCs and sodium hyaluronate }\end{array}$ & $\begin{array}{c}\text { To evaluate enhancement of } \\
\text { healing of anterior cruciate } \\
\text { ligament injury using } \\
\text { UCB-MSCs }\end{array}$ & UCB-MSCs \\
\hline NCT02034786 & I & $\begin{array}{l}\text { Lipodystro- } \\
\text { phies,aesthetics } \\
\text { procedure }\end{array}$ & $\begin{array}{l}\text { Transdermal injection of a } \\
\text { filler agent composed of MSCs } \\
\text { from autologous adipose tissue } \\
\text { associated with HA }\end{array}$ & $\begin{array}{l}\text { To study the efficacy and safety } \\
\text { of transplantation of autologous } \\
\text { adipose stem cells with HA for } \\
\text { the treatment of lipodystrophy }\end{array}$ & $\begin{array}{l}\text { Autologous } \\
\text { MSCs from } \\
\text { adipose tissue }\end{array}$ \\
\hline NCT02698813 & I & $\begin{array}{l}\text { Senescence } \\
\text { wrinkles, acne, } \\
\text { pitting scar }\end{array}$ & $\begin{array}{l}\text { Transdermal injection of } \\
\text { UC-MSCs and HA }\end{array}$ & $\begin{array}{l}\text { To evaluate the safety and } \\
\text { efficacy of the injectable filler } \\
\text { agent composed of UC-MSCs } \\
\text { and HA for the improvement of } \\
\text { wrinkles, acne and pitting scar }\end{array}$ & UC-MSCs \\
\hline NCT01981330 & I & $\begin{array}{l}\text { Severe hoarseness } \\
\text { and vocal fold } \\
\text { scarring }\end{array}$ & $\begin{array}{l}\text { Single injection of BM-MSCs } \\
\text { mixed with a carrier } \\
\text { hyaluronan gel }\end{array}$ & $\begin{array}{l}\text { To evaluate the efficacy of the } \\
\text { injection of BM-MSCs mixed } \\
\text { with and without hyaluronan } \\
\text { gel to heal scarred vocal folds }\end{array}$ & $\begin{array}{l}\text { Autologous } \\
\text { BM-MSCs }\end{array}$ \\
\hline NCT03101163 & II & $\begin{array}{l}\text { Degeneration } \\
\text { and disorder of } \\
\text { articular knee } \\
\text { cartilage }\end{array}$ & IA injections of PBSCs and HA & $\begin{array}{l}\text { To evaluate and determine } \\
\text { whether PBSCs with HA } \\
\text { therapy can improve functional } \\
\text { outcome and reduce pain of the } \\
\text { knee joint better than a } \\
\text { standard treatment }\end{array}$ & $\begin{array}{l}\text { Autologous } \\
\text { PBSCs }\end{array}$ \\
\hline
\end{tabular}

from multiple BM donors, has been tested together with HA in order to increase the engraftment and chondrogenic activity. In the preclinical model of OA, Stempeucel ${ }^{\circledR}$, at both low and high doses and supplemented with HA, significantly reduces pain and repairs damaged articular cartilage in rats (Gupta et al., 2016). In the clinical study, IA administration of Stempeuce ${ }^{\circledR}$ followed by injection of HA appears to be safe, showing a trend towards improvement in all subjective parameters (VAS, ICOAP and WOMACOA scores) in the low-dose group. However, when compared to a placebo (Plasmalyte-A, Baxter Healthcare Ltd., Norfolk, England) no therapeutic efficacy is observed, which the authors attribute to the small number of patients enrolled in the study.
Another drawback observed in the study is that the treatment with higher dose groups (50, 75 and $150 \times 10^{6}$ cells) causes knee pain and swelling (Gupta et al., 2016; Web ref. 11).

HA together with MSCs tested for meniscus repair In a double-blind clinical study with Chondrogen ${ }^{\circledR}$ (Osiris Therapeutics, Baltimore, MD, USA) a preparation of adult MSCs in a solution containing HA shows that a single injection of Chondrogen ${ }^{\circledR}$ into the knee of patients following partial meniscectomy can significantly increase meniscal volume and reduce knee pain as compared with the use of $\mathrm{HA}$ alone, when measured 12 months post meniscectomy (Web ref. 12). Patients with osteoarthritic changes 
at the time of surgery experience a reduction in pain following the treatment due to $\mathrm{HA}$ - which is a commonly used treatment for OA pain (Concoff et al., 2017) possibly providing some benefit to the patients (Vangsness et al., 2014). These studies help to elucidate the role of MSCs in knee-tissue regeneration and to increase the potential of HA in cell therapy. The use of HA-based scaffolds loaded with cells that fit the cartilage lesion is the promising strategy of a clinical trial currently recruiting participants to evaluate the safety and efficacy of Hyalofast ${ }^{\circledR}$ (Anika Therapeutics, Inc.), a biodegradable hyaluronanbased $\left(\mathrm{HYAFF}^{\circledR}\right)$ scaffold, and BMAC in the treatment of cartilage defects of the knee. The purpose of the study is to evaluate the efficacy of a Hyalofast ${ }^{\circledR}$ scaffold, which acts as a biodegradable support for the autologous BMAC and to compare this treatment to microfracture, an arthroscopic surgical technique providing stem cells and growth factors from the BM to aid cartilage repair (Web ref. 13). Cavallo et al. (2013) demonstrated in vitro that BMCs grown onto $\mathrm{HYAFF}^{\circledR}-11$ can differentiate into chondrogenic cells by expressing and producing specific ECM molecules. Additionally, a previous study with 20 patients older than 45 years demonstrated the safety and efficiency of treating full thickness cartilage lesions with Hyalofast ${ }^{\circledR}$ soaked in BMACs, showing that indication to surgery should not be based only on age, but rather on lesion size and number. However, a long-term comparative study with a larger sample and with a detailed radiological analysis is still needed to ultimately assess the potential of this technique (Gobbi et al., 2017).

Another product, consisting of immune-selected allogenic MPCs derived from adult BM, is being tested in combination with HA and HA alone as an active comparator for the treatment of anterior cruciate ligament injury (Web ref. 14), degenerative disc disease (Web ref. 15) and is currently recruiting participants with chronic lower back pain for a new phase III study (Web ref. 16). Preliminary results from the anterior cruciate ligament injury study showed that IA administration of MPCs is safe and well tolerated, both MPCs + HA- and HA-injected groups show symptomatic improvement; however, the MPC + HA-treated group exhibits larger changes from baseline (Wang et al., 2017b).

The implantation of autologous MSCs from adipose tissue was tested in combination with a medical fill composed of an HA gel cross-linked with butanediol diglycidyl ether (Tissuefill ${ }^{\circledR}$ NeoGenesis Co., Ltd., Seoul, Korea) as a cell carrier in patients with chronic lower back pain caused by lumbar disc degeneration (Web ref. 17). Ahn et al. (2015) showed that co-administration with Tissuefill ${ }^{\circledR}$ can enhance the efficacy of intradiscally injected MSCs. The results from the phase I clinical trial confirm the safety and tolerability of co-injection of MSCs and the HA derivative in patients with IVD degeneration. Significant improvements in pain are demonstrated in 6 out of 10 patients and rehydration of the disc in
3 out of 6 patients throughout the 12-month duration. The exact mechanism by which the combined implantation of MSCs and the HA derivative leads to improvement of chronic discogenic lower back pain remains unclear, however, the authors assume that injection of MSCs into the degenerated disc improves ECM production by the degenerated host nucleus pulposus cells and modulates their immunological response to inflammatory cytokines that could potentially inhibit the inflammatory cascade, thereby preventing ingrowth of pain-inducing vasculature and nerve fibres. On the other hand, suspension of the cells in HA derivative for coadministration may prevent cell leakage, reduce the risk of uncontrolled differentiation of MSCs into osteoblasts and enhance cell attachment and cell survival (Kumar et al., 2017).

Among the few MSC-based products that are approved worldwide, one combines sodium hyaluronate with human UC-MSCs. Cartistem ${ }^{\circledR}$ (Medipost Co., Ltd, Bundang-gu, Korea) has been approved for sale in Korea by the Korean FDA since January 2012 and is intended to be used as a singledose therapeutic agent for cartilage regeneration in cartilage defects of the knee. Currently, there is an ongoing clinical study to assess the efficacy of Cartistem ${ }^{\circledR}$ in articular cartilage defects (Web ref. 18) and another one for the healing of the anterior cruciate ligament injury (Web ref. 19). Results from phase I/II clinical trial in a small sample size $(n=7)$ investigating this product for the regeneration of articular cartilage defects in OA patients show an acceptable efficacy and safety profile due to improvements in pain and function at 24 weeks post-transplantation that are maintained without significant deterioration up to 7 years. The repair site is restored with hyaline-like cartilage tissue, which seems to contribute to the observed persistence of the regenerated cartilage with durable improvement in pain and function (Park et al., 2017).

As a biocompatible filler agent, HA has been used for over 25 years for cosmetic purposes and for reconstruction of soft tissues. Transdermal injection of HA in combination with autologous MSCs from adipose tissue is currently being evaluated for treatment of lipoatrophy, lipodystrophy types characterised by subcutaneous adipose tissue atrophy due to trauma, tumour resection and congenital defects. The objective is to evaluate if this combination is more effective in tissue reconstitution, providing volume and cell differentiation and increased production of ECM than the injection of adipose tissue only (Web ref. 20). In this light, another randomised study will be open for participant recruitment in order to evaluate the safety and efficacy of the transdermal injection of a filler agent composed of UC-MSCs and HA for the improvement of wrinkles, acne and pitting scar; injection of HA only will be used as an active comparator (Web ref. 21). The healing of vocal fold scarring, to treat severe hoarseness and vocal fold scarring, is also being tested in an ongoing clinical trial using a single injection of autologous MSCs from 
BM alone or MSCs mixed with hyaluronan gel as a carrier into the vocal folds (Web ref. 22).

\section{Conclusions and future perspectives}

Several chemical strategies have been developed to modulate the HA mechanical, chemical and biological properties with the objective of broadening HA usefulness in cell therapy and TE. Moreover, there are increasing clinical trials based on the combination of stem cells with HA or HA derivatives. These facts unequivocally show the virtues of using HA derivatives for in vitro or in vivo applications, alone or in combination with cells.

HA chains present several sites amenable to chemical modification, leading to the development of a wide array of derivatives aiming to reproduce the native tissue properties. Novel formulations that improve safety of HA crosslinking in situ and prolonged residence time are one of the main issues. To improve mechanical properties of HA hydrogels, concentrations of crosslinked HA have been modulated, opening the way to scaffolds with tuneable degradation rate adapted to the tissue of the injury. Moreover, with the aim to provide good mechanical properties, scaffolds are being created by the combination of HA with other polymers.

New strategies to enhance the bio-compatibility and biological cell response include combination of HA with materials such as fibronectin, laminin or small peptides, among others. In particular, decellularised tissue is a promising material that can be processed together with HA to produce a gel to provide mechanical, biophysical and biochemical cues to cells. Furthermore, the current state of research has emphasised on the use of HA hydrogels combined with drugs, plasmids or growth factors to guide endogenous stem cells towards a specific injured area or/and promote tissue regeneration. The possibility of administering or growing stem cells in scaffolds or hydrogels made of HA has created high expectations in this field, allowing in vivo cell differentiation after a surgical implant.

Towards next generation products, the functionalisation of conductive polymers by incorporating HA for enhancing their physicochemical and biological functionality may provide new anisotropic scaffolds to mimic the structure and function of native electroactive tissue. Currently, new preparations based on HA for viscosupplementation, including the combination of HA or its derivatives with PRP or MSCs derived from BMC, may offer an advanced treatment for regeneration, in particular of cartilage tissue, that could potentially provide better functional outcomes. Moreover, clinical trials are focussing on evaluating the efficacy and safety of stem cells together with HA formulations. Preliminary results, mainly directed to cartilage and skin regeneration or restoration, show that combination of HA and stem cells is safe and improves pain reduction and therapeutic efficacy by enhancing cell survival and tissue restoration.

Finally, novel techniques have also been employed towards fabricating HA-based scaffolds. The development of 3D bioprinting technologies have emerged as a powerful tool for TE due to the ability to mimic the 3D structure of any tissue. So, the combinations of HA-based bioinks, cells and biomaterials will allow obtaining mimetic tissues with similar characteristic to native ones and will accelerate the clinical application of that technology.

The development of new HA-based functionalised scaffolds and the use of HA or HA derivatives as bioinks that mimic ECM for 3D bioprinting in combination with different materials and cells are issues that will be the focus of future research for regenerative medicine purposes. It is expected that clinical translation of stem-cells-HA-based therapies will be a reality in the next few years.

\section{Acknowledgments}

All authors wrote, reviewed and approved the final version of the manuscript.

GJ acknowledges the Junta de Andalucía for providing a post-doctoral fellowship. CA acknowledges the predoctoral fellowship from the Spanish Ministry of Education, Culture and Sports (BOE-A-2014-13539). ELR acknowledges the MINECO for providing a post-doctoral fellowship through the project RTC-2016-5451-1.

This work was supported by the Ministerio de Economía, Industria y Competitividad (FEDER funds, project RTC-2016-5451-1) and FIS2017-85954-R (Agencia Estatal de Investigación, AEI, Spain, cofunded by Fondo Europeo de Desarrollo Regional, ERDF, European Union) and by Junta de Andalucía (Spain) project P12-FQM-2721. Additional support was provided by grants from ADVANCE (CAT) with the support of ACCIÓ (Catalonia Trade \& Investment; Generalitat de Catalunya).

\section{References}

Adams ME, Atkinson MH, Lussier AJ, Schulz JI, Siminovitch KA, Wade JP, Zummer M (1995) The role of viscosupplementation with hylan G-F 20 (Synvisc) in the treatment of osteoarthritis of the knee: a Canadian multicenter trial comparing hylan G-F 20 alone, hylan G-F 20 with non-steroidal antiinflammatory drugs (NSAIDs) and NSAIDs alone. Osteoarthr Cartil 3: 213-225.

Ahn J, Park E, Kim BJ, Kim J-S, Choi B, Lee S-H, Han I (2015) Transplantation of human Wharton's jelly-derived mesenchymal stem cells highly expressing TGF $\beta$ receptors in a rabbit model of disc degeneration. Stem Cell Res Ther 6: 190. DOI: 10.1186/ s13287-015-0183-1. 
Altman RD, Bedi A, Karlsson J, Sancheti P, Schemitsch E (2016) Product differences in intraarticular hyaluronic acids for osteoarthritis of the knee. Am J Sports Med 44: 2158-2165.

Andia I, Abate M (2014) Knee osteoarthritis: hyaluronic acid, platelet-rich plasma or both in association? Expert Opin Biol Ther 14: 635-649.

Antunes JC, Oliveira JM, Reis RL, Soria JM, Gomez-Ribelles JL, Mano JF (2010) Novel poly(Llactic acid)/hyaluronic acid macroporous hybrid scaffolds: characterization and assessment of cytotoxicity. J Biomed Mater Res A 94: 856-869.

Atzei A, Calcagni M, Breda B, Fasolo G, Pajardi G, Cugola L (2007) Clinical evaluation of a hyaluronanbased gel following microsurgical reconstruction of peripheral nerves of the hand. Microsurgery 27: 2-7.

Aulin C, Bergman K, Jensen-Waern M, Hedenqvist P, Hilborn J, Engstrand T (2011) In situ cross-linkable hyaluronan hydrogel enhances chondrogenesis. J Tissue Eng Regen Med 5: 188-196.

Ballios BG, Cooke MJ, van der Kooy D, Shoichet MS (2010) A hydrogel-based stem cell delivery system to treat retinal degenerative diseases. Biomaterials 31: 2555-2564.

Ballios BG, Cooke MJ, Donaldson L, Coles BLK, Morshead CM, van der Kooy D, Shoichet MS (2015) A hyaluronan-based injectable hydrogel improves the survival and integration of stem cell progeny following transplantation. Stem Cell Reports 4: 10311045.

Barbucci R, Rappuoli R, Borzacchiello A, Ambrosio L (2000) Synthesis, chemical and rheological characterization of new hyaluronic acid-based hydrogels. J Biomater Sci Polym Ed 11: 383-399.

Bardelli S, Moccetti M (2017) Remodeling the human adult stem cell niche for regenerative medicine applications. Stem Cells Int 2017: 6406025. DOI:10.1155/2017/6406025.

Benedetti L, Cortivo R, Berti T, Berti A, Pea F, Mazzo M, Moras M, Abatangelo G (1993) Biocompatibility and biodegradation of different hyaluronan derivatives (Hyaff) implanted in rats. Biomaterials 14: 1154-1160.

Bowman S, Awad ME, Hamrick MW, Hunter M, Fulzele S (2018) Recent advances in hyaluronic acid based therapy for osteoarthritis. Clin Transl Med 7: 6. DOI: 10.1186/s40169-017-0180-3.

Brännvall K, Bergman K, Wallenquist U, Svahn S, Bowden T, Hilborn J, Forsberg-Nilsson K (2007) Enhanced neuronal differentiation in a threedimensional collagen-hyaluronan matrix. J Neurosci Res 85: 2138-2146.

Brown AC, Rowe JA, Barker TH (2011) Guiding epithelial cell phenotypes with engineered integrinspecific recombinant fibronectin fragments. Tissue Eng Part A 17: 139-150.

Burdick JA, Prestwich GD (2011) Hyaluronic acid hydrogels for biomedical applications. Adv Mater 23: H41-56.

Cagini C, Torroni G, Fiore T, Cerquaglia A, Lupidi M, Aragona P, Iaccheri B (2017) Tear film stability in
Sjögren syndrome patients treated with hyaluronic acid versus crosslinked hyaluronic acid-based eye drops. J Ocul Pharmacol Ther 33: 539-542.

Cai Y, López-Ruiz E, Wengel J, Creemers LB, Howard KA (2017) A hyaluronic acid-based hydrogel enabling CD44-mediated chondrocyte binding and gapmer oligonucleotide release for modulation of gene expression in osteoarthritis. J Control Release 253: 153-159.

Camci-Unal G, Aubin H, Ahari AF, Bae H, Nichol JW, Khademhosseini A (2010) Surface-modified hyaluronic acid hydrogels to capture endothelial progenitor cells. Soft Matter 6: 5120-5126.

Campbell KA, Erickson BJ, Saltzman BM, Mascarenhas R, Bach BR, Cole BJ, Verma NN (2015) Is local viscosupplementation injection clinically superior to other therapies in the treatment of osteoarthritis of the knee: a systematic review of overlapping meta-analyses. Arthrosc J Arthrosc Relat Surg 31: 2036-2045.

Canadas RF, Pirraco RP, Oliveira JM, Reis RL, Marques AP (2018) Stem cells for osteochondral regeneration. Adv Exp Med Biol 1059: 219-240.

Caravaggi C, De Giglio R, Pritelli C, Sommaria M, Dalla Noce S, Faglia E, Mantero M, Clerici G, Fratino P, Dalla Paola L, Mariani G, Mingardi R, Morabito A (2003) HYAFF 11-based autologous dermal and epidermal grafts in the treatment of noninfected diabetic plantar and dorsal foot ulcers: a prospective, multicenter, controlled, randomized clinical trial. Diabetes Care 26: 2853-2859.

Cavallo C, Desando G, Columbaro M, Ferrari A, Zini N, Facchini A, Grigolo B (2013) Chondrogenic differentiation of bone marrow concentrate grown onto a hylauronan scaffold: rationale for its use in the treatment of cartilage lesions. J Biomed Mater Res Part A 101A: 1559-1570.

Cengiz IF, Oliveira JM, Reis RL (2018) PRP therapy. Adv Exp Med Biol 1059: 241-253.

Chan DD, Xiao WF, Li J, de la Motte CA, Sandy JD, Plaas A (2015) Deficiency of hyaluronan synthase 1 (Has1) results in chronic joint inflammation and widespread intra-articular fibrosis in a murine model of knee joint cartilage damage. Osteoarthritis Cartilage 23: 1879-1889.

Chen WH, Lo WC, Hsu WC, Wei HJ, Liu HY, Lee CH, Tina Chen SY, Shieh YH, Williams DF, Deng WP (2014) Synergistic anabolic actions of hyaluronic acid and platelet-rich plasma on cartilage regeneration in osteoarthritis therapy. Biomaterials 35: 9599-9607.

Chiari C, Koller U, Dorotka R, Eder C, Plasenzotti R, Lang S, Ambrosio L, Tognana E, Kon E, Salter D, Nehrer S (2006) A tissue engineering approach to meniscus regeneration in a sheep model. Osteoarthritis Cartilage 14: 1056-1065.

Collins MN, Birkinshaw C (2008) Physical properties of crosslinked hyaluronic acid hydrogels. J Mater Sci Mater Med 19: 3335-3343.

Collins MN, Birkinshaw C (2011) Morphology of crosslinked hyaluronic acid porous hydrogels. J Appl Polym Sci 120: 1040-1049. 
Collins MN, Birkinshaw C (2013) Hyaluronic acid based scaffolds for tissue engineering - a review. Carbohydr Polym 92: 1262-1279.

Crescenzi V, Cornelio L, Di Meo C, Nardecchia S, Lamanna R (2007) Novel hydrogels via click chemistry: synthesis and potential biomedical applications. Biomacromolecules 8: 1844-1850.

Concoff A, Sancheti P, Niazi F, Shaw P, Rosen J (2017) The efficacy of multiple versus single hyaluronic acid injections: a systematic review and meta-analysis. BMC Musculoskelet Disor 18: 542. DOI: 10.1186/s12891-017-1897-2.

Cui FZ, Tian W M, Hou SP, Xu QY, Lee I-S, Tian WM (2006) Hyaluronic acid hydrogel immobilized with RGD peptides for brain tissue engineering. J Mater Sci Mater Med 17: 1393-1401.

Dai W-L, Zhou A-G, Zhang H, Zhang J (2017) Efficacy of platelet-rich plasma in the treatment of knee osteoarthritis: a meta-analysis of randomized controlled trials. Arthrosc J Arthrosc Relat Surg 33: 659-670.

Davidenko N, Campbell JJ, Thian ES, Watson CJ, Cameron RE (2010) Collagen-hyaluronic acid scaffolds for adipose tissue engineering. Acta Biomater 6: 3957-3968.

de Oliveira JD, Carvalho LS, Gomes AMV, Queiroz LR, Magalhães BS, Parachin NS (2016) Genetic basis for hyper production of hyaluronic acid in natural and engineered microorganisms. Microb Cell Fact 15: 119. DOI: 10.1186/s12934-016-0517-4.

Deng Y, Sun AX, Overholt KJ, Yu GZ, Fritch MR, Alexander PG, Shen H, Tuan RS, Lin H (2019) Enhancing chondrogenesis and mechanical strength retention in physiologically relevant hydrogels with incorporation of hyaluronic acid and direct loading of TGF- $\beta$. Acta Biomater 83: 167-176.

Derakhshanfar S, Mbeleck R, Xu K, Zhang X, Zhong W, Xing M (2018) 3D bioprinting for biomedical devices and tissue engineering: a review of recent trends and advances. Bioact Mater 3: 144156.

Dicker KT, Gurski LA, Pradhan-Bhatt S, Witt RL, Farach-Carson MC, Jia X (2014) Hyaluronan: a simple polysaccharide with diverse biological functions. Acta Biomater 10: 1558-1570.

Durrie DS, Wolsey D, Thompson V, Assang C, Mann B, Wirostko B (2018) Ability of a new crosslinked polymer ocular bandage gel to accelerate reepithelialization after photorefractive keratectomy. J Cataract Refract Surg 44: 369-375.

Ekaputra AK, Prestwich GD, Cool SM, Hutmacher DW (2008) Combining electrospun scaffolds with electrosprayed hydrogels leads to threedimensional cellularization of hybrid constructs. Biomacromolecules 9: 2097-2103.

Ekaputra AK, Prestwich GD, Cool SM, Hutmacher DW (2011) The three-dimensional vascularization of growth factor-releasing hybrid scaffold of poly (epsilon-caprolactone)/collagen fibers and hyaluronic acid hydrogel. Biomaterials 32: 8108-8017.
Emadedin M, Aghdami N, Taghiyar L, Fazeli R, Moghadasali R, Jahangir S, Farjad R, Eslaminejad MB (2012) Intra-articular injection of autologous mesenchymal stem cells in six patients with knee osteoarthritis. Arch Iran Med 15: 422-428.

Erickson IE, Kestle SR, Zellars KH, Farrell MJ, Kim M, Burdick JA, Mauck RL (2012) High mesenchymal stem cell seeding densities in hyaluronic acid hydrogels produce engineered cartilage with native tissue properties. Acta Biomater 8: 3027-3034.

Eslami M, Vrana NE, Zorlutuna P, Sant S, Jung S, Masoumi N, Khavari-Nejad RA, Javadi G, Khademhosseini A (2014) Fiber-reinforced hydrogel scaffolds for heart valve tissue engineering. J Biomater 29: 399-410.

Espandar L, Bunnell B, Wang GY, Gregory P, McBride C, Moshirfar M (2012) Adipose-derived stem cells on hyaluronic acid-derived scaffold: a new horizon in bioengineered cornea. Arch Ophthalmol 130: 202-208.

Estades-Rubio FJ, Reyes-Martín A, MoralesMarcos V, García-Piriz M, García-Vera JJ, Perán M, Marchal JA, Montañez-Heredia E (2017) Knee viscosupplementation: cost-effectiveness analysis between stabilized hyaluronic acid in a single injection versus five injections of standard hyaluronic acid. Int J Mol Sci 18. DOI: 10.3390/ijms18030658.

Fakhari A, Berkland C (2013) Applications and emerging trends of hyaluronic acid in tissue engineering, as a dermal filler and in osteoarthritis treatment. Acta Biomater 9: 7081-7092.

Filardo G, Di Matteo B, Di Martino A, Merli ML, Cenacchi A, Fornasari P, Marcacci M, Kon E (2015) Platelet-rich plasma intra-articular knee injections show no superiority versus viscosupplementation: a randomized controlled trial. Am J Sports Med. 43: 1575-1582.

Fraser JR, Laurent TC, Laurent UB (1997) Hyaluronan: its nature, distribution, functions and turnover. J Intern Med 242: 27-33.

Furlan S, La Penna G, Perico A, Cesàro A (2005) Hyaluronan chain conformation and dynamics. Carbohydr Res 340: 959-970.

Gálvez-Martín P, Martin MJ, Ruiz MA, Clares B (2017) Encapsulation in cell therapy: methodologies, materials, and clinical applications. Curr Pharm Biotechnol 18: 365-377.

Geronemus RG, Bank DE, Hardas B, Shamban A, Weichman BM, Murphy DK (2017) Safety and effectiveness of VYC-15L, a hyaluronic acid filler for lip and perioral enhancement. Dermatologic Surg 43: 396-404.

Ghosh K, Ren X-D, Shu XZ, Prestwich GD, Clark RAF (2006) Fibronectin functional domains coupled to hyaluronan stimulate adult human dermal fibroblast responses critical for wound healing. Tissue Eng 12: 601-613.

Gobbi A, Scotti C, Karnatzikos G, Mudhigere A, Castro M, Peretti GM (2017) One-step surgery with multipotent stem cells and hyaluronan-based scaffold 
for the treatment of full-thickness chondral defects of the knee in patients older than 45 years. Knee Surg Sports Traumatol Arthrosc 25: 2494-2501.

Gramlich WM, Kim IL, Burdick JA (2013) Synthesis and orthogonal photopatterning of hyaluronic acid hydrogels with thiol-norbornene chemistry. Biomaterials 34: 9803-9811.

Gravante G, Sorge R, Merone A, Tamisani AM, Di Lonardo A, Scalise A, Doneddu G, Melandri D, Stracuzzi G, Onesti MG, Cerulli P, Pinn R, Esposito G (2010) Hyalomatrix PA in burn care practice: results from a national retrospective survey, 2005 to 2006. Ann Plast Surg 64: 69-79.

Gudowska M, Cylwik B, Chrostek L (2017) The role of serum hyaluronic acid determination in the diagnosis of liver fibrosis. Acta Biochim Pol 64: 451457.

Gupta PK, Chullikana A, Rengasamy M, Shetty N, Pandey V, Agarwal V, Wagh SY, Vellotare PK, Damodaran D, Viswanathan P, Thej C, Balasubramanian S, Majumdar A Sen (2016) Efficacy and safety of adult human bone marrow-derived, cultured, pooled, allogeneic mesenchymal stromal cells (Stempeucel ${ }^{\circledR}$ ): preclinical and clinical trial in osteoarthritis of the knee joint. Arthritis Res Ther 18: 301. DOI: 10.1186/s13075-016-1195-7.

Ha C-W, Park Y-B, Chung J-Y, Park Y-G (2015) Cartilage repair using composites of human umbilical cord blood-derived mesenchymal stem cells and hyaluronic acid hydrogel in a minipig model. Stem Cells Transl Med 4: 1044-1051.

Hadley HS, Stanley BJ, Fritz MC, Hauptman JG, Steficek BA (2013) Effects of a cross-linked hyaluronic acid based gel on the healing of open wounds in dogs. Vet Surg 42: 161-169.

Hargittai I, Hargittai M (2008) Molecular structure of hyaluronan: an introduction. Struct Chem 19: 697717.

Hemshekhar M, Thushara RM, Chandranayaka S, Sherman LS, Kemparaju K, Girish KS (2016) Emerging roles of hyaluronic acid bioscaffolds in tissue engineering and regenerative medicine. Int J Biol Macromol 86: 917-928.

Highley CB, Prestwich GD, Burdick JA (2016) Recent advances in hyaluronic acid hydrogels for biomedical applications. Curr Opin Biotechnol 40: 35-40.

Hosack LW, Firpo MA, Scott JA, Prestwich GD, Peattie RA (2008) Microvascular maturity elicited in tissue treated with cytokine-loaded hyaluronanbased hydrogels. Biomaterials 29: 2336-2347.

Hou S, Xu Q, Tian W, Cui F, Cai Q, Ma J, Lee IS (2005) The repair of brain lesion by implantation of hyaluronic acid hydrogels modified with laminin. J Neurosci Methods 148: 60-70.

Hu Y, Chen J, Fan T, Zhang Y, Zhao Y, Shi X, Zhang Q (2017) Biomimetic mineralized hierarchical hybrid scaffolds based on in situ synthesis of nano-hydroxyapatite/chitosan/chondroitin sulfate/ hyaluronic acid for bone tissue engineering. Colloids Surf B Biointerfaces 157: 93-100.
Huerta-Angeles G, Němcová M, Příkopová E, Šmejkalová D, Pravda M, Kučera L, Velebný V (2012) Reductive alkylation of hyaluronic acid for the synthesis of biocompatible hydrogels by click chemistry. Carbohydr Polym 90: 1704-1711.

Huh SW, Shetty AA, Ahmed S, Lee DH, Kim SJ (2016) Autologous bone-marrow mesenchymal cell induced chondrogenesis (MCIC). J Clin Orthop Trauma 7: 153-156.

Ifkovits JL, Tous E, Minakawa M, Morita M, Robb JD, Koomalsingh KJ, Gorman JH, Gorman RC, Burdick J a (2010) Injectable hydrogel properties influence infarct expansion and extent of postinfarction left ventricular remodeling in an ovine model. Proc Natl Acad Sci 107: 11507-11512.

Isacke Isacke CM, Yarwood H (2002) The hyaluronan receptor, CD44. Int J Biochem Cell Biol. 34: 718-721.

Ishida O, Tanaka Y, Morimoto I, Takigawa M, Eto S (1997) Chondrocytes are regulated by cellular adhesion through cd44 and hyaluronic acid pathway. J Bone Miner Res 12: 1657-1663.

Itano N, Sawai T, Yoshida M, Lenas P, Yamada Y, Imagawa $M$, Shinomura T, Hamaguchi M, Yoshida Y, Ohnuki Y, Miyauchi S, Spicer AP, McDonald JA, Kimata K (1999) Three isoforms of mammalian hyaluronan synthases have distinct enzymatic properties. J Biol Chem 274: 25085-25092.

Jeong SI, Jun ID, Choi MJ, Nho YC, Lee YM, Shin H (2008) Development of electroactive and elastic nanofibres that contain polyaniline and poly(Llactide-co-epsilon-caprolactone) for the control of cell adhesion. Macromol Biosci 8: 627-637.

Jha AK, Mathur A, Svedlund FL, Ye J, Yeghiazarians Y, Healy KE (2015) Molecular weight and concentration of heparin in hyaluronic acid-based matrices modulates growth factor retention kinetics and stem cell fate. J Control Release 209: 308-316.

Jones IA, Togashi R, Wilson ML, Heckmann N, Vangsness CT (2018) Intra-articular treatment options for knee osteoarthritis. Nat Rev Rheumatol 15: 77-90. Kaleka CC, Zucconi E, Vieira T da S, Secco M, Ferretti M, Cohen M (2018) Evaluation of different commercial hyaluronic acids as a vehicle for injection of human adipose-derived mesenchymal stem cells. Rev. Bras. Ortop 53: 557-563.

Kesti M, Müller M, Becher J, Schnabelrauch M, D’Este M, Eglin D, Zenobi-Wong M (2015) A versatile bioink for three-dimensional printing of cellular scaffolds based on thermally and photo-triggered tandem gelation. Acta Biomater 11: 162-172.

Khaldoyanidi SK, Goncharova V, Mueller B, Schraufstatter IU (2014) Hyaluronan in the healthy and malignant hematopoietic microenvironment. Adv Cancer Res 123: 149-189.

Khalil S, Sun W (2009) Bioprinting endothelial cells with alginate for $3 \mathrm{D}$ tissue constructs. J Biomech Eng 131: 111002. DOI: 10.1115/1.3128729.

Khunmanee S, Jeong Y, Park H (2017) Crosslinking method of hyaluronic-based hydrogel for biomedical applications. J Tissue Eng. 8: 2041731417726464 . DOI: $10.1177 / 2041731417726464$. 
Kim DH, Richardson-Burns SM, Hendricks JL, Sequera C, Martin DC (2007) Effect of immobilized nerve growth factor on conductive polymers: electrical properties and cellular response. Adv Funct Mater 17: 79-86.

Kim HJ, Kim KK, Park IK, Choi BS, Kim JH, Kim MS (2012) Hybrid scaffolds composed of hyaluronic acid and collagen for cartilage regeneration. Tissue Eng Regen Med 9: 57-62.

Kim H, Jeong H, Han S, Beack S, Hwang BW, Shin M, Oh SS, Hahn SK (2017) Hyaluronate and its derivatives for customized biomedical applications. Biomaterials 123: 155-171.

Kirker KR, Luo Y, Nielson JH, Shelby J, Prestwich GD (2002) Glycosaminoglycan hydrogel films as biointeractive dressings for wound healing. Biomaterials 23: 3661-3671.

Kisiel M, Martino MM, Ventura M, Hubbell JA, Hilborn J, Ossipov DA (2013) Improving the osteogenic potential of BMP-2 with hyaluronic acid hydrogel modified with integrin-specific fibronectin fragment. Biomaterials 34: 704-712.

Knopf-Marques H, Pravda M, Wolfova L, Velebny V, Schaaf P, Vrana NE, Lavalle P (2016) Hyaluronic acid and its derivatives in coating and delivery systems: applications in tissue engineering, regenerative medicine and immunomodulation. Adv Healthc Mater 5: 2841-2855.

Kontturi L-S, Järvinen E, Muhonen V, Collin EC, Pandit AS, Kiviranta I, Yliperttula M, Urtti A (2014) An injectable, in situ forming type II collagen/ hyaluronic acid hydrogel vehicle for chondrocyte delivery in cartilage tissue engineering. Drug Deliv Transl Res 4: 149-158.

Kornev VA, Grebenik EA, Solovieva AB, Dmitriev RI, Timashev PS (2018) Hydrogel-assisted neuroregeneration approaches towards brain injury therapy: a state-of-the-art review. Comput Struct Biotechnol J 16: 488-502.

Kumar H, Ha D-H, Lee E-J, Park JH, Shim JH, Ahn T-K, Kim K-T, Ropper AE, Sohn S, Kim C-H, Thakor DK, Lee S-H, Han I-B (2017) Safety and tolerability of intradiscal implantation of combined autologous adipose-derived mesenchymal stem cells and hyaluronic acid in patients with chronic discogenic low back pain: 1-year follow-up of a phase I study. Stem Cell Res Ther 8: 262. DOI: 10.1186/s13287-0170710-3.

Kuna VK, Padma AM, Håkansson J, Nygren J, Sjöback R, Petronis S, Sumitran-Holgersson S (2017) Significantly accelerated wound healing of fullthickness skin using a novel composite gel of porcine acellular dermal matrix and human peripheral blood cells. Cell Transplant 26: 293-307.

Kuo JW, Prestwich GD (2011) Comprehensive biomaterials. Elsevier 2: 239-259.

Kurisawa M, Chung JE, Yang YY, Gao SJ, Uyama H (2005) Injectable biodegradable hydrogels composed of hyaluronic acid-tyramine conjugates for drug delivery and tissue engineering. Chem Commun 14: 4312-4314.
Lai JY (2014) Relationship between structure and cytocompatibility of divinyl sulfone cross-linked hyaluronic acid. Carbohydr Polym 101: 203-212.

Lam J, Truong NF, Segura T (2014) Design of cell-matrix interactions in hyaluronic acid hydrogel scaffolds. Acta Biomater 10: 1571-1580.

Lamo-Espinosa JM, Mora G, Blanco JF, GraneroMoltó F, Nuñez-Córdoba JM, Sánchez-Echenique C, Bondía JM, Aquerreta JD, Andreu EJ, Ornilla E, Villarón EM, Valentí-Azcárate A, Sánchez-Guijo F, Del Cañizo MC, Valentí-Nin JR, Prósper F (2016) Intra-articular injection of two different doses of autologous bone marrow mesenchymal stem cells versus hyaluronic acid in the treatment of knee osteoarthritis: multicenter randomized controlled clinical trial (phase I/II). J Transl Med 14: 246. DOI: 10.1186/s12967-016-0998-2.

Lamo-Espinosa JM, Mora G, Blanco JF, GraneroMoltó F, Núñez-Córdoba JM, López-Elío S, Andreu E, Sánchez-Guijo F, Aquerreta JD, Bondía JM, ValentíAzcárate A, del Consuelo del Cañizo M, Villarón EM, Valentí-Nin JR, Prósper F (2018) Intra-articular injection of two different doses of autologous bone marrow mesenchymal stem cells versus hyaluronic acid in the treatment of knee osteoarthritis: long-term follow up of a multicenter randomized controlled clinical trial (phase I/II). J Transl Med 16: 213. DOI: 10.1186/s12967-018-1591-7.

Lana JFSD, Weglein A, Sampson SE, Vicente EF, Huber SC, Souza C V, Ambach MA, Vincent H, Urban-Paffaro A, Onodera CMK, AnnichinoBizzacchi JM, Santana MHA, Belangero WD (2016) Randomized controlled trial comparing hyaluronic acid, platelet-rich plasma and the combination of both in the treatment of mild and moderate osteoarthritis of the knee. J Stem Cells Regen Med 12: 69-78.

Laroui H, Grossin L, Léonard M, Stoltz J-F, Gillet P, Netter P, Dellacherie E (2007) Hyaluronatecovered nanoparticles for the therapeutic targeting of cartilage. Biomacromolecules 8: 3879-3885.

Laurent TC, Fraser JR (1992) Hyaluronan. FASEB J 6: 2397-2404.

Lebaschi A, Nakagawa Y, Wada S, Cong GT, Rodeo SA (2017) Tissue-specific endothelial cells: a promising approach for augmentation of soft tissue repair in orthopedics. Ann N Y Acad 1410: 44-56.

Lee JY, Spicer AP (2000) Hyaluronan: a multifunctional, megaDalton, stealth molecule. Curr Opin Cell Biol 12: 581-586.

Li H, Xue Y, Jia B, Bai Y, Zuo Y, Wang S, Zhao Y, Yang W, Tang H (2018) The preparation of hyaluronic acid grafted pullulan polymers and their use in the formation of novel biocompatible wound healing film. Carbohydr Polym 188: 92-100.

Lisignoli G, Toneguzzi S, Zini N, Piacentini A, Cristino S, Tschon M, Grassi F, Fini M, Giardino R, Maraldi NM, Facchini A (2003) Hyaluronanbased biomaterial (Hyaff-11) as scaffold to support mineralization of bone marrow stromal cells. Chir Organi Mov 88: 363-367. 
Liu L, Liu Y, Li J, Du G, Chen J (2011) Microbial production of hyaluronic acid: current state, challenges, and perspectives. Microb Cell Fact 10: 99. DOI: 10.1186/1475-2859-10-99.

Liu Y, Wang R, Zarembinski TI, Doty N, Jiang C, Regatieri C, Zhang X, Young MJ (2013) The application of hyaluronic acid hydrogels to retinal progenitor cell transplantation. Tissue Eng Part A 19: 135-142.

Loebel C, Rodell CB, Chen MH, Burdick JA (2017) Shear-thinning and self-healing hydrogels as injectable therapeutics and for 3D-printing. Nat Protoc 12: 1521-1541.

López-Ruiz E, Jiménez G, García MÁ, Antich C, Boulaiz H, Marchal JA, Perán M (2016) Polymers, scaffolds and bioactive molecules with therapeutic properties in osteochondral pathologies: what's new? Expert Opin Ther Pat 26: 877-890.

Lu HD, Zhao HQ, Wang K, Lv LL (2011) Novel hyaluronic acid-chitosan nanoparticles as non-viral gene delivery vectors targeting osteoarthritis. Int J Pharm 420: 358-365.

Lu H, Lv L, Dai Y, Wu G, Zhao H, Zhang F (2013) Porous chitosan scaffolds with embedded hyaluronic acid/chitosan/plasmid-DNA nanoparticles encoding TGF- $\beta 1$ induce DNA controlled release, transfected chondrocytes, and promoted cell proliferation. PLoS One 8: e69950. DOI: 10.1371/journal.pone.0069950.

Mahler GJ, Butcher JT (2011) Inflammatory regulation of valvular remodeling: the good(?), the bad, and the ugly. Int J Inflam 2011: 721419. DOI: 10.4061/2011/721419.

Mainil-Varlet P, Schiavinato A, Ganster MM (2013) Efficacy evaluation of a new hyaluronan derivative HYADD $^{\circledR} 4-G$ to maintain cartilage integrity in a rabbit model of osteoarthritis. Cartilage 4: 28-41.

Mano JF, Silva GA, Azevedo HS, Malafaya PB, Sousa RA, Silva SS, Boesel LF, Oliveira JM, Santos TC, Marques AP, Neves NM, Reis RL (2007) Natural origin biodegradable systems in tissue engineering and regenerative medicine: present status and some moving trends. J. R. Soc. Interface 4: 999-1030.

Masoumi N, Annabi N, Assmann A, Larson BL, Hjortnaes J, Alemdar N, Kharaziha M, Manning KB, Mayer JE, Khademhosseini A (2014) Tri-layered elastomeric scaffolds for engineering heart valve leaflets. Biomaterials 35: 7774-7785.

Masters KS, Shah DN, Walker G, Leinwand LA, Anseth KS (2004) Designing scaffolds for valvular interstitial cells: cell adhesion and function on naturally derived materials. J Biomed Mater Res A 71: $172-180$.

Masters KS, Shah DN, Leinwand LA, Anseth KS (2005) Crosslinked hyaluronan scaffolds as a biologically active carrier for valvular interstitial cells. Biomaterials 26: 2517-2525.

Mehra TD, Ghosh K, Shu XZ, Prestwich GD, Clark RAF (2006) Molecular stenting with a crosslinked hyaluronan derivative inhibits collagen gel contraction. J Invest Dermatol 126: 2202-2209.
Mironov V, Kasyanov V, Zheng Shu X, Eisenberg C, Eisenberg L, Gonda S, Trusk T, Markwald RR, Prestwich GD (2005) Fabrication of tubular tissue constructs by centrifugal casting of cells suspended in an in situ crosslinkable hyaluronan-gelatin hydrogel. Biomaterials 26: 7628-7635.

Monteiro IP, Shukla A, Marques AP, Reis RL, Hammond PT (2015) Spray-assisted layer-by-layer assembly on hyaluronic acid scaffolds for skin tissue engineering. J Biomed Mater ResPart A 103: 330-340.

Mothe AJ, Tam RY, Zahir T, Tator CH, Shoichet MS (2013) Repair of the injured spinal cord by transplantation of neural stem cells in a hyaluronanbased hydrogel. Biomaterials 34: 3775-3783.

Mouser VHM, Abbadessa A, Levato R, Hennink WE, Vermonden T, Gawlitta D, Malda J (2017) Development of a thermosensitive HAMA-containing bio-ink for the fabrication of composite cartilage repair constructs. Biofabrication 9: 015026. DOI: 10.1088/1758-5090/aa6265.

Murakami T, Otsuki S, Okamoto Y, Nakagawa K, Wakama H, Okuno N, Neo M (2018) Hyaluronic acid promotes proliferation and migration of human meniscus cells via a CD44-dependent mechanism. Connect Tissue Res 26: 1-11.

Murphy CA, Costa JB, Silva-Correia J, Oliveira JM, Reis RL, Collins MN (2018) Biopolymers and polymers in the search of alternative treatments for meniscal regeneration: state of the art and future trends. Appl Mater Today 12: 51-71.

Murugan Girija D, Kalachaveedu M, Ranga Rao S, Subbarayan R (2018) Transdifferentiation of human gingival mesenchymal stem cells into functional keratinocytes by Acalypha indica in three-dimensional microenvironment. J Cell Physiol 233: 8450-8457.

Nakamura K, Yokohama S, Yoneda M, Okamoto S, Tamaki Y, Ito T, Okada M, Aso K, Makino I (2004) High, but not low, molecular weight hyaluronan prevents T-cell-mediated liver injury by reducing proinflammatory cytokines in mice. J Gastroenterol 39: 346-354.

Nicholas MN, Jeschke MG, Amini-Nik S (2016) Methodologies in creating skin substitutes. Cell Mol Life Sci 73: 3453-3472.

Niki Y, Takeuchi T, Nakayama M, Nagasawa H, Kurasawa T, Yamada H, Toyama Y, Miyamoto T (2012) Clinical significance of cartilage biomarkers for monitoring structural joint damage in rheumatoid arthritis patients treated with anti-TNF therapy. PLoS One 7: e37447. DOI: 10.1371/journal.pone.0037447.

Ortuño-Lizarán I, Vilariño-Feltrer G, MartínezRamos C, Pradas MM, Vallés-Lluch A (2016) Influence of synthesis parameters on hyaluronic acid hydrogels intended as nerve conduits. Biofabrication 8: 045011. DOI: 10.1088/1758-5090/8/4/045011.

Özgenel GY (2003) Effects of hyaluronic acid on peripheral nerve scarring and regeneration in rats. Microsurgery 23: 575-581.

Park H, Larson BL, Kolewe ME, Vunjak-Novakovic G, Freed LE (2014) Biomimetic scaffold combined 
with electrical stimulation and growth factor promotes tissue engineered cardiac development. Exp Cell Res 321: 297-306.

Park JK, Shim JH, Kang KS, Yeom J, Jung HS, Kim JY, Lee KH, Kim TH, Kim SY, Cho DW, Hahn SK (2011) Solid free-form fabrication of tissue-engineering scaffolds with a poly(lactic-co-glycolic acid) grafted hyaluronic acid conjugate encapsulating and intact bone morphogenetic protein-2/poly(ethylene glycol) complex. Adv Funct Mater 21: 2906-2912.

Park YB, Ha CW, Lee C-H, Yoon YC, Park Y-G (2017) Cartilage regeneration in osteoarthritic patients by a composite of allogeneic umbilical cord blood-derived mesenchymal stem cells and hyaluronate hydrogel: results from a clinical trial for safety and proof-of-concept with 7 years of extended follow-up. Stem Cells Transl Med 6: 613-621.

Park Y-B, Song M, Lee C-H, Kim J-A, Ha C-W (2015) Cartilage repair by human umbilical cord blood-derived mesenchymal stem cells with different hydrogels in a rat model. J Orthop Res 33: 1580-1586.

Pederzini LA, Milandri L, Tosi M, Prandini M, Nicoletta F (2013) Preliminary clinical experience with hyaluronan anti-adhesion gel in arthroscopic arthrolysis for posttraumatic elbow stiffness. J Orthop Traumatol 14: 109-114.

Perng C-K, Wang Y-J, Tsi C-H, Ma H (2011) In vivo angiogenesis effect of porous collagen scaffold with hyaluronic acid oligosaccharides. J Surg Res 168: 9-15.

Pescosolido L, Schuurman W, Malda J, Matricardi P, Alhaique F, Coviello T, Van Weeren PR, Dhert WJA, Hennink WE, Vermonden T (2011) Hyaluronic acid and dextran-based semi-IPN hydrogels as biomaterials for bioprinting. Biomacromolecules 12: 1831-1838.

Prestwich GD, Marecak DM, Marecek JF, Vercruysse KP, Ziebell MR (1998) Controlled chemical modification of hyaluronic acid: synthesis, applications, and biodegradation of hydrazide derivatives. J Control Release 53: 93-103.

Prestwich GD (2007) Simplifying the extracellular matrix for 3-D cell culture and tissue engineering: A pragmatic approach. J Cell Biochem 101: 1370-1383.

Prestwich GD, Kuo J (2008) Chemically-modified HA for therapy and regenerative medicine. Curr Pharm Biotechnol 9: 242-245.

Prestwich GD (2011) Hyaluronic acid-based clinical biomaterials derived for cell and molecule delivery in regenerative medicine. J Control Release 155: 193-199.

Prestwich GD, Erickson IE, Zarembinski TI, West M, Tew WP (2012) The translational imperative: making cell therapy simple and effective. Acta Biomater 8: 4200-4207.

Priano F (2017) Early efficacy of intra-articular HYADD $^{\circledR} 4$ (Hymovis $^{\circledR}$ ) injections for symptomatic knee osteoarthritis. Joints 5: 79-84.

Purcell BP, Elser JA, Mu A, Margulies KB, Burdick JA (2012) Synergistic effects of SDF-1alpha chemokine and hyaluronic acid release from degradable hydrogels on directing bone marrow derived cell homing to the myocardium. Biomaterials 33: 78497857.

Radhakumary C, Nandkumar AM, Nair PD (2011) Hyaluronic acid-g-poly(HEMA) copolymer with potential implications for lung tissue engineering. Carbohydr Polym 85: 439-445.

Ratliff BB, Ghaly T, Brudnicki P, Yasuda K, Rajdev M, Bank M, Mares J, Hatzopoulos AK, Goligorsky MS (2010) Endothelial progenitors encapsulated in bioartificial niches are insulated from systemic cytotoxicity and are angiogenesis competent. Am J Physiol Ren Physiol 299: 178-186.

Ravina K, Briggs DI, Kislal S, Warraich Z, Nguyen T, Lam RK, Zarembinski TI, Shamloo M (2018) Intracerebral delivery of brain-derived neurotrophic factor using $\mathrm{HyStem}^{\circledR}$-C hydrogel implants improves functional recovery and reduces neuroinflammation in a rat model of ischemic stroke. Int J Mol Sci 19: pii: E3782. DOI: 10.3390/ijms19123782. DOI: 10.3390/ ijms19113322.

Rho JG, Han HS, Han JH, Lee H, Nguyen VQ, Lee WH, Kwon S, Heo S, Yoon J, Shin HH, Lee E, Kang H, Yang S, Lee EK, Park JH, Kim W (2018) Self-assembled hyaluronic acid nanoparticles: implications as a nanomedicine for treatment of type 2 diabetes. J Control Release 279: 89-98.

Roffi A, Nakamura N, Sanchez M, Cucchiarini M, Filardo G (2018) Injectable systems for intra-articular delivery of mesenchymal stromal cells for cartilage treatment: a systematic review of preclinical and clinical evidence. Int J Mol Sci 19: 3322. DOI: 10.3390/ ijms19113322.

Ruel-Gariépy E, Leroux J-C (2004) In situ-forming hydrogels-review of temperature-sensitive systems. Eur J Pharm Biopharm 58: 409-426.

Russo F, D'Este M, Vadalà G, Cattani C, Papalia R, Alini M, Denaro V (2016) Platelet rich plasma and hyaluronic acid blend for the treatment of osteoarthritis: rheological and biological evaluation. PLoS One 11: e0157048. DOI: 10.1371/journal. pone.0157048.

Sampson S, Botto-van Bemden A, Aufiero D (2013) Autologous bone marrow concentrate: review and application of a novel intra-articular orthobiologic for cartilage disease. Physician Sport Med 41: 7-18.

Sanz-Garcia A, Oliver-de-la-Cruz J, Mirabet V, Gandía C, Villagrasa A, Sodupe E, Escobedo-Lucea C (2015) Heart valve tissue engineering: how far is the bedside from the bench? Expert Rev Mol Med 17: e16. DOI: 10.1017/erm.2015.15.

Saw K-Y, Anz A, Siew-Yoke Jee C, Merican S, Ching-Soong Ng R, Roohi SA, Ragavanaidu K (2013) Articular cartilage regeneration with autologous peripheral blood stem cells versus hyaluronic acid: a randomized controlled trial. Arthrosc J Arthrosc Relat Surg 29: 684-694.

Schanté CE, Zuber G, Herlin C, Vandamme TF (2011) Chemical modifications of hyaluronic acid for the synthesis of derivatives for a broad range of 
biomedical applications. Carbohydr Polym 85: 469489.

Schmidt JR, Vogel S, Moeller S, Kalkhof S, Schubert K, von Bergen M, Hempel U (2018) Sulfated hyaluronic acid and dexamethasone possess a synergistic potential in the differentiation of osteoblasts from human bone marrow stromal cells. J Cell Biochem. DOI:10.1002/jcb.28158.

A, Picart C, Senger B, Schaaf P, Voegel JC, Frisch B (2007) Layer-by-layer films from hyaluronan and amine-modified hyaluronan. Langmuir 23: 2655-2662.

Seidlits SK, Drinnan CT, Petersen RR, Shear JB, Suggs LJ, Schmidt CE (2011) Fibronectin-hyaluronic acid composite hydrogels for three-dimensional endothelial cell culture. Acta Biomater 7: 2401-2409.

Shi G, Zhang Z, Rouabhia M (2008) The regulation of cell functions electrically using biodegradable polypyrrole-polylactide conductors. Biomaterials 29: 3792-3798.

Shim J-H, Jang K-M, Hahn SK, Park JY, Jung H, Oh K, Park KM, Yeom J, Park SH, Kim SW, Wang JH, Kim K, Cho D-W (2016) Three-dimensional bioprinting of multilayered constructs containing human mesenchymal stromal cells for osteochondral tissue regeneration in the rabbit knee joint. Biofabrication 8: 014102. DOI: $10.1088 / 1758-5090 / 8 / 1 / 014102$.

Shu XZ, Liu Y, Luo Y, Roberts MC, Prestwich GD (2002) Disulfide cross-linked hyaluronan hydrogels. Biomacromolecules 3: 1304-1311.

Shu XZ, Ghosh K, Liu Y, Palumbo FS, Luo Y, Clark RA, Prestwich GD (2004) Attachment and spreading of fibroblasts on an RGD peptide-modified injectable hyaluronan hydrogel. J Biomed Mater Res A 68: 365375.

Shu XZ, Ahmad S, Liu Y, Prestwich GD (2006) Synthesis and evaluation of injectable, in situ crosslinkable synthetic extracellular matrices for tissue engineering. J Biomed Mater Res A 79: 902-912.

Silva LP da, Pirraco RP, Santos TC, NovoaCarballal R, Cerqueira MT, Reis RL, Correlo VM, Marques AP (2016) Neovascularization induced by the hyaluronic acid-based spongy-like hydrogels degradation products. ACS Appl Mater Interfaces 8: 33464-33474.

Simman R, Mari W, Younes S, Wilson M (2018) Use of hyaluronic acid-based biological bilaminar matrix in wound bed preparation: a case series. Eplasty 18: e17.

Skardal A, Zhang J, McCoard L, Xu X, Oottamasathien S, Prestwich GD (2010) Photocrosslinkable hyaluronan-gelatin hydrogels for two-step bioprinting. Tissue Eng Part A 16: 26752685.

Stefanski A-L, Tomiak C, Pleyer U, Dietrich T, Burmester GR, Dörner T (2017) The diagnosis and treatment of Sjögren's syndrome. Dtsch Arztebl Int 114: 354-361.

Skardal A, Devarasetty M, Kang H-W, Mead I, Bishop C, Shupe T, Lee SJ, Jackson J, Yoo J, Soker S, Atala A (2015) A hydrogel bioink toolkit for mimicking native tissue biochemical and mechanical properties in bioprinted tissue constructs. Acta Biomater 25: 24-34.

Smith RR uckdeschel, Marbán E, Marbán L (2013) Enhancing retention and efficacy of cardiospherederived cells administered after myocardial infarction using a hyaluronan-gelatin hydrogel. Biomatter 3: pii: e24490. DOI: 10.4161/biom.24490.

Souness A, Zamboni F, Walker GM, Collins MN (2018) Influence of scaffold design on 3D printed cell constructs. J Biomed Mater Res B Appl Biomater 106: 533-545.

Stichler S, Böck T, Paxton N, Bertlein S, Levato R, Schill V, Smolan W, Malda J, Teßmar J, Blunk T, Groll J (2017) Double printing of hyaluronic acid/poly(glycidol) hybrid hydrogels with poly( $\varepsilon$ caprolactone) for MSC chondrogenesis. Biofabrication 9: 044108. DOI: 10.1088/1758-5090/aa8cb7.

Takahashi S, Yamazoe H, Sassa F, Suzuki H, Fukuda J (2009) Preparation of coculture system with three extracellular matrices using capillary force lithography and layer-by-layer deposition. J Biosci Bioeng 108: 544-550.

Tamer TM, Collins MN, Valachová K, Hassan MA, Omer AM, Mohy-Eldin MS, Švík K, Jurčík R, Ondruška L, Biró C, Albadarin AB, Šoltés L (2018) MitoQ loaded chitosan-hyaluronan composite membranes for wound healing. Mater (Basel, Switzerland) 11: pii: E569. DOI: 10.3390/ma11040569.

Thomas M, Willerth SM (2017) 3-D bioprinting of neural tissue for applications in cell therapy and drug screening. Front Bioeng Biotechnol 5: 69. DOI: 10.3389/fbioe.2017.00069.

Toh WS, Lee EH, Guo XM, Chan JKY, Yeow $\mathrm{CH}$, Choo AB, Cao $\mathrm{T}$ (2010) Cartilage repair using hyaluronan hydrogel-encapsulated human embryonic stem cell-derived chondrogenic cells. Biomaterials 31: 6968-6980.

Toole BP (2004) Hyaluronan: from extracellular glue to pericellular cue. Nat Rev Cancer 4: 528-539.

Uccioli L (2003) A clinical investigation on the characteristics and outcomes of treating chronic lower extremity wounds using the tissuetech autograft system. Int J Low Extrem Wounds 2: 140-151.

Valachová K, Baňasová M, Topol'ská D, Sasinková V, Juránek I, Collins MN, Šoltés L (2015) Influence of tiopronin, captopril and levamisole therapeutics on the oxidative degradation of hyaluronan. Carbohydr Polym 134: 516-523.

Valachová K, Topol'ská D, Mendichi R, Collins MN, Sasinková V, Šoltés L (2016) Hydrogen peroxide generation by the Weissberger biogenic oxidative system during hyaluronan degradation. Carbohydr Polym 148: 189-193.

Valderrábano M (2007) Influence of anisotropic conduction properties in the propagation of the cardiac action potential. Prog Biophys Mol Biol 94: 144-168.

Vangsness CT, Farr J, Boyd J, Dellaero DT, Mills CR, LeRoux-Williams M (2014) Adult human 
mesenchymal stem cells delivered via intra-articular injection to the knee following partial medial meniscectomy: a randomized, double-blind, controlled study. J Bone Joint Surg Am 96: 90-98.

Volpi N, Schiller J, Stern R, Soltés L (2009) Role, metabolism, chemical modifications and applications of hyaluronan. Curr Med Chem 16: 1718-1745.

Wang LS, Chung JE, Pui-Yik Chan P, Kurisawa M (2010) Injectable biodegradable hydrogels with tunable mechanical properties for the stimulation of neurogenesic differentiation of human mesenchymal stem cells in 3D culture. Biomaterials 31: 1148-1157.

Wang S, Guan S, Wang J, Liu H, Liu T, Ma X, Cui Z (2017a) Fabrication and characterization of conductive poly (3,4-ethylenedioxythiophene) doped with hyaluronic acid/poly (l-lactic acid) composite film for biomedical application. J Biosci Bioeng 123: 116-125.

Wang TW, Spector M (2009) Development of hyaluronic acid-based scaffolds for brain tissue engineering. Acta Biomater 5: 2371-2384.

Wang Y, Shimmin A, Ghosh P, Marks P, Linklater J, Connell D, Hall S, Skerrett D, Itescu S, Cicuttini FM (2017b) Safety, tolerability, clinical, and joint structural outcomes of a single intra-articular injection of allogeneic mesenchymal precursor cells in patients following anterior cruciate ligament reconstruction: a controlled double-blind randomised trial. Arthritis Res Ther 19: 180. DOI: 10.1186/s13075017-1391-0.

Wei YT, Tian WM, Yu X, Cui FZ, Hou SP, Xu QY, Lee I-S (2007) Hyaluronic acid hydrogels with IKVAV peptides for tissue repair and axonal regeneration in an injured rat brain. Biomed Mater 2: S142-S146.

Wende FJ, Gohil S, Mojarradi H, Gerfaud T, Nord LI, Karlsson A, Boiteau J-G, Kenne AH, Sandström C (2016) Determination of substitution positions in hyaluronic acid hydrogels using NMR and MS based methods. Carbohydr Polym 136: 1348-1357.

Wenz A, Borchers K, Tovar GEM, Kluger PJ (2017) Bone matrix production in hydroxyapatitemodified hydrogels suitable for bone bioprinting. Biofabrication 9: 044103. DOI: 10.1088/1758-5090/ aa91ec.

Wu CC, Chen WH, Zao B, Lai PL, Lin TC, Lo HY, Shieh YH, Wu CH, Deng WP (2011) Regenerative potentials of platelet-rich plasma enhanced by collagen in retrieving pro-inflammatory cytokineinhibited chondrogenesis. Biomaterials 32: 5847-5854.

Wu Y, Stoddart MJ, Wuertz-Kozak K, Grad S, Alini M, Ferguson SJ (2017) Hyaluronan supplementation as a mechanical regulator of cartilage tissue development under joint-kinematic-mimicking loading. J R Soc Interface 14: pii: 20170255. DOI: 10.1098/rsif.2017.0255.

Xu X, Jha AK, Duncan RL, Jia X (2011) Heparindecorated, hyaluronic acid-based hydrogel particles for the controlled release of bone morphogenetic protein 2. Acta Biomater 7: 3050-3059.

Xu X, Jha AK, Harrington DA, Farach-Carson MC, Jia X (2012) Hyaluronic acid-based hydrogels: from a natural polysaccharide to complex networks. Soft Matter 8: 3280-3294.

Ye Y, Zhou X, Mao S, Zhang J, Lin B (2018) Platelet rich plasma versus hyaluronic acid in patients with hip osteoarthritis: a meta-analysis of randomized controlled trials. Int J Surg 53: 279-287.

Zamboni F, Collins MN (2017) Cell based therapeutics in type 1 diabetes mellitus. Int J Pharm 521: 346-356.

Zamboni F, Vieira S, Reis RL, Miguel Oliveira J, Collins MN (2018) The potential of hyaluronic acid in immunoprotection and immunomodulation: chemistry, processing and function. Prog Mater Sci 97: $97-122$.

Zhang F, He C, Cao L, Feng W, Wang H, Mo X, Wang J (2011a) Fabrication of gelatin-hyaluronic acid hybrid scaffolds with tunable porous structures for soft tissue engineering. Int J Biol Macromol 48: 474481.

Zhang H, Wang C, Li H, Huang Y, Li Z (2018) Intra-articular platelet-rich plasma versus hyaluronic acid in the treatment of knee osteoarthritis: a metaanalysis. Drug Des Devel Ther 12: 445-453.

Zhang L, Xiao Y, Jiang B, Fan H, Zhang X (2010) Effect of adipic dihydrazide modification on the performance of collagen/hyaluronic acid scaffold. J Biomed Mater Res Appl Biomater 92: 307-316.

Zhang L, Li K, Xiao W, Zheng L, Xiao Y, Fan H, Zhang X (2011b) Preparation of collagen-chondroitin sulfate-hyaluronic acid hybrid hydrogel scaffolds and cell compatibility in vitro. Carbohydr Polym 84: 118-125.

Zhang LM, Wu CX, Huang JY, Peng XH, Chen P, Tang S-Q (2012) Synthesis and characterization of a degradable composite agarose/HA hydrogel. Carbohydr Polym 88: 1445-1452.

Zhou M, Hou J, Zhong Z, Hao N, Lin Y, Li C (2018) Targeted delivery of hyaluronic acid-coated solid lipid nanoparticles for rheumatoid arthritis therapy. Drug Deliv 25: 716-722.

Zhu D, Wang H, Trinh P, Heilshorn SC, Yang F (2017) Elastin-like protein-hyaluronic acid (ELP-HA) hydrogels with decoupled mechanical and biochemical cues for cartilage regeneration. Biomaterials 127: 132-140.

Zille H, Paquet J, Henrionnet C, Scala-Bertola J, Leonard M, Six JL, Deschamp F, Netter P, Vergès J, Gillet P, Grossin L (2010) Evaluation of intraarticular delivery of hyaluronic acid functionalized biopolymeric nanoparticles in healthy rat knees. Biomed Mater Eng 20: 235-242.

\section{Web References}

1.https://clinicaltrials.gov/ct2/show/NCT01586312 [07-02-2019]

2. https://clinicaltrials.gov/ct2/show/NCT02776943 [07-02-2019]

3. https://clinicaltrials.gov/ct2/show/NCT02580695 [07-02-2019] 
4. https://clinicaltrials.gov/ct2/show/NCT02967874

[07-02-2019]

5. https://clinicaltrials.gov/ct2/show/NCT02958267 [07-02-2019]

6. https://clinicaltrials.gov/ct2/show/NCT02674399

[07-02-2019]

7. https://clinicaltrials.gov/ct2/show/study/ NCT01076673 [07-02-2019]

8. https://clinicaltrials.gov/ct2/show/NCT03101163 [07-02-2019]

9. https://clinicaltrials.gov/ct2/show/record/ NCT02123368 [07-02-2019]

10. https://clinicaltrials.gov/ct2/show/study/ NCT01459640 [07-02-2019]

11. https://clinicaltrials.gov/ct2/show/study/ NCT01453738 [07-02-2019]

12. https://clinicaltrials.gov/ct $2 /$ show/ NCT00225095 [07-02-2019]

13. https://clinicaltrials.gov/ct2/show/ NCT02659215 [07-02-2019]

14. https://clinicaltrials.gov/ct2/show/ NCT01088191 [07-02-2019]

15. https://clinicaltrials.gov/ct2/show/study/ NCT01290367 [07-02-2019]

16. https://clinicaltrials.gov/ct2/show/ NCT02412735 [07-02-2019]

17. https://clinicaltrials.gov/ct2/show/study/ NCT02338271 [07-02-2019]

18. http://clinicaltrials.gov/show/NCT01733186 [07-02-2019]

19. https://clinicaltrials.gov/ct2/show/ NCT02755376 [07-02-2019]

20. https://clinicaltrials.gov/ct2/show/ NCT02034786 [07-02-2019]

21. https://clinicaltrials.gov/ct2/show/study/ NCT02698813 [07-02-2019]

22. https://clinicaltrials.gov/show/NCT01981330 [07-02-2019]

\section{Discussion with Reviewer}

Declan Devine: The authors illustrated a wide range of uses for HA. However, since native bone is a composite material, would HA be an appropriate matrix material for use in orthopaedic composites?

Authors: HA is an ideal material for natural scaffolds thanks to its unique biocompatibility, chemical functionalisation and degradability. Several studies have suggested that HA-containing scaffold materials are efficacious in bone-repair processes (Faruq et al., 2017; Hamlet et al., 2017; Hu et al., 2017; Turnbull et al., 2018, additional references). These studies assessed the utility of injectable HA gels for the treatment of bone-related diseases due to the involvement of HA in several biological processes, such as osteoinduction and wound healing (Suzuki et al., 2014, additional reference). Due to the strong effects of HA on cell motility and cell-cell interactions and with the aim of improving tissue-scaffold interactions, other studies have explored the possibility of developing scaffold made of bioceramics and biopolymer, such as HA, resulting in the formation of composites for bone regeneration (Nguyen and Lee, 2014; Poldervaart et al., 2017, additional references). In addition, the bone scaffold surface coating with HA is very effective in enhancing osteogenesis (Kang et al., 2011; Motamedian et al., 2015, additional references). Finally, regarding orthopaedic materials, HA and some of its composites offer a well-established longterm safety profile and a proven ability to reduce bacterial adhesion and biofilm formation on to the surface of various biomaterials commonly used in orthopaedics, trauma and dental surgery (Romanò et al., 2017, additional reference).

\section{Additional References}

Faruq O, Kim B, Padalhin AR, Lee GH, Lee B-T (2017) A hybrid composite system of biphasic calcium phosphate granules loaded with hyaluronic acidgelatin hydrogel for bone regeneration. J Biomater Appl 32: 433-445.

Hamlet SM, Vaquette C, Shah A, Hutmacher DW, Ivanovski S (2017) 3-dimensional functionalized polycaprolactone-hyaluronic acid hydrogel constructs for bone tissue engineering. J Clin Periodontol 44: 428437.

Hu Y, Chen J, Fan T, Zhang Y, Zhao Y, Shi X, Zhang Q (2017) Biomimetic mineralized hierarchical hybrid scaffolds based on in situ synthesis of nano-hydroxyapatite/chitosan/chondroitin sulfate/ hyaluronic acid for bone tissue engineering. Colloids Surf B Biointerfaces 157: 93-100.

Kang S-W, Kim J-S, Park K-S, Cha B-H, Shim J-H, Kim JY, Cho D-W, Rhie J-W, Lee S-H (2011) Surface modification with fibrin/hyaluronic acid hydrogel on solid-free form-based scaffolds followed by BMP-2 loading to enhance bone regeneration. Bone 48: 298306.

Motamedian SR, Hosseinpour S, Ahsaie MG, Khojasteh A (2015) Smart scaffolds in bone tissue engineering: a systematic review of literature. World J Stem Cells 7: 657-668.

Nguyen TBL, Lee B-T (2014) A combination of biphasic calcium phosphate scaffold with hyaluronic acid-gelatin hydrogel as a new tool for bone regeneration. Tissue Eng Part A 20: 1993-2004.

Poldervaart MT, Goversen B, de Ruijter M, Abbadessa A, Melchels FPW, Öner FC, Dhert WJA, Vermonden T, Alblas J (2017) 3D bioprinting of methacrylated hyaluronic acid (MeHA) hydrogel with intrinsic osteogenicity. PLoS One 12: e0177628. DOI:10.1371/journal.pone.0177628.

Romanò CL, De Vecchi E, Bortolin M, Morelli I, Drago L (2017) Hyaluronic acid and its composites as a local antimicrobial/antiadhesive barrier. J Bone Jt Infect 2: 63-72. 
Suzuki K, Anada T, Miyazaki T, Miyatake N, Honda Y, Kishimoto KN, Hosaka M, Imaizumi H, Itoi E, Suzuki O (2014) Effect of addition of hyaluronic acids on the osteoconductivity and biodegradability of synthetic octacalcium phosphate. Acta Biomater 10: 531-543.
Turnbull G, Clarke J, Picard F, Riches P, Jia L, Han F, Li B, Shu W (2018) 3D bioactive composite scaffolds for bone tissue engineering. Bioact Mater 3: 278-314.

Editor's note: The Scientific Editor responsible for this paper was Chris Evans. 